OPEN ACCESS

Edited by:

Victor Borovkov,

South-Central University for

Nationalities, China

Reviewed by:

Tomas Torres,

Autonomous University of

Madrid, Spain

Norio Shibata,

Nagoya Institute of Technology, Japan

Dmitry Valentinovich Konarev,

Institute of Problems of Chemical

Physics (RAS), Russia

*Correspondence:

Nagao Kobayashi

nagaok@shinshu-u.ac.jp;

nagaok@m.tohoku.ac.jp

Specialty section:

This article was submitted to

Supramolecular Chemistry,

a section of the journal

Frontiers in Chemistry

Received: 18 August 2020

Accepted: 28 September 2020

Published: 19 October 2020

Citation:

Okada Y, Hoshi T and Kobayashi N (2020) Recent Progress in

Optically-Active Phthalocyanines and

Their Related Azamacrocycles.

Front. Chem. 8:595998.

doi: 10.3389/fchem.2020.595998

\section{Recent Progress in Optically-Active Phthalocyanines and Their Related Azamacrocycles}

\author{
Yusuke Okada ${ }^{1}$, Tomonori Hoshi ${ }^{2}$ and Nagao Kobayashi ${ }^{1 *}$ \\ ${ }^{1}$ Faculty of Textile Science and Technology, Shinshu University, Ueda, Japan, ${ }^{2}$ Clinical Research, Innovation and Education \\ Center, Tohoku University Hospital, Sendai, Japan
}

Optically-active phthalocyanines (Pcs) and related macrocycles reported in the 2010-2020 period are introduced in this review. They are grouped into several categories: (1) chiral binaphthyl-containing Pcs, (2) optically active alkyl chain-containing Pcs, (3) chiral axial ligand- coordinated or -linked Pcs, (4) chiral subphthalocyanines (SubPcs), and (5) related azamacrocycles. For each compound, the structure and important characteristics are summarized.

Keywords: chiral, optically active, phthalocyanine, binaphthyl, circular dichroism, porphyrin

\section{INTRODUCTION}

Optically-active or chiral macrocycles of azaporphyrinoids have attracted the attention of synthetic and theoretical chemists, as well as researchers in the fields of applied chemistry and physics, and natural science (Kadish et al., 2003a). Although some small chiral molecules including porphyrins have been studied due to their relatively easy synthesis and specific optical, medicinal, and catalytic properties (Kadish et al., 2000, 2003b), optically active azaporphyrins including phthalocyanines (Pcs) have mainly been introduced by researchers who want to have intense CD signal in the visible region, since azaporphyrins have theoretically more intense absorption band than normal porphyrins in the visible region (the so-called Q band). In the twenty-first century, several review articles have already been published (Kobayashi, 2001, 2010, 2012; Lu and Kobayashi, 2016). However, in this review, we summarize the reports on chiral Pcs and their related macrocycles published in the last 10 years, between 2010 and 2020. After collecting papers on chiral, i.e., optically-active Pcs and related macrocycles, we observed that they are roughly grouped into five categories: (1) chiral binaphthyl (Binap) and related aromatic molecule-containing Pcs, (2) optically-active alkyl chain-containing Pcs, (3) chiral axial ligand-coordinated or -linked Pcs, (4) chiral subphthalocyanines (SubPcs), and (5) related azamacrocycles. Papers containing chiral binaphthyls number more than half of these publications, and this may be due to several factors: easy preparation of binaphthyl-linked precursors, very little possibility of racemization under the experimental conditions, and an expected large circular dichroism (CD) intensity. Reports on optically-active alkyl chain-containing Pcs are also frequently seen, and these are generally used to examine liquid crystalline properties, since long alkyl chain (generally more than 10 carbon)containing Pcs are known to form liquid crystals (= mesophase) by varying the temperature. Other interesting azamacrocycles which can be congeners of or related to Pcs have also appeared from several groups across the world. We introduce these in order in this review. 


\section{BINAP AND BINAP-RELATED SUBSTITUENT-LINKED SYSTEMS}

\section{Synthesis}

Figure 1 summarizes the structures grouped into this category (in the case of 3D-structures, $\mathbf{6 - 1 1}$, only $R$-enantiomers which have an anti-clockwise binaphthyl structure are shown). In 2012, the synthesis of compound $\mathbf{1}$ from precursor a was reported (Wang et al., 2012). Previously, similar compounds $\mathbf{4}$ had been reported from a precursor containing sulfur instead of oxygen in a (i.e., $\mathbf{a}^{\prime}$ ) (Kobayashi et al., 1999a) due to the then-known low racemization probability of a' under the experimental conditions. However, it was possible to prepare a from commercially available 2,2'-dihydroxybinaphthyl and 4,5-dichlorophthalonitrile in one step without racemization, while the cyclic tetramerization step leading to $\mathbf{1}$ was also free from racemization. Accordingly, both $\mathbf{a}$ and $\mathbf{1}$ were later used in chiral Pc chemistry. For example, the zinc complex of $\mathbf{1}$ could form a cofacial dimer by stepwise coordination of two quinuclidine molecules (GiménezAgulló et al., 2016), which was confirmed by the change of absorption spectra and ${ }^{1} \mathrm{H}-\mathrm{NMR}$ signal. In addition, $\mathbf{1}$ was used to construct chiral bis(phthalocyaninato)yttrium doubledecker complexes 8 and 9 (Zhou et al., 2014), as well as a porphyrin-Pc heteroleptic rare-earth triple decker complex 10 (Wang et al., 2014). These were synthesized by metal-free $\mathbf{1}$ and $\mathrm{Y}(\mathrm{acac})_{3} \cdot n \mathrm{H}_{2} \mathrm{O}$ or $\mathbf{1}$ and metal-free porphyrin or $\mathrm{Pc}$ in the presence of $\mathrm{Y}(\mathrm{acac})_{3} \cdot n \mathrm{H}_{2} \mathrm{O}$ or Dy(acac $)_{3} \cdot n \mathrm{H}_{2} \mathrm{O}$, followed by purification using column chromatography.

Compound 2 was obtained by ring-expansion reaction of a SubPc with isoindole derivative $\mathbf{d}$ which was obtained by bubbling ammonia gas to dinitrile a (Zhao et al., 2015). The ring-expansion using SubPc and isoindoline derivatives per se was introduced in 1990 as a means to obtain mono-substituted ABBB-type Pcs (Kobayashi et al., 1990, 1999b). Since then,

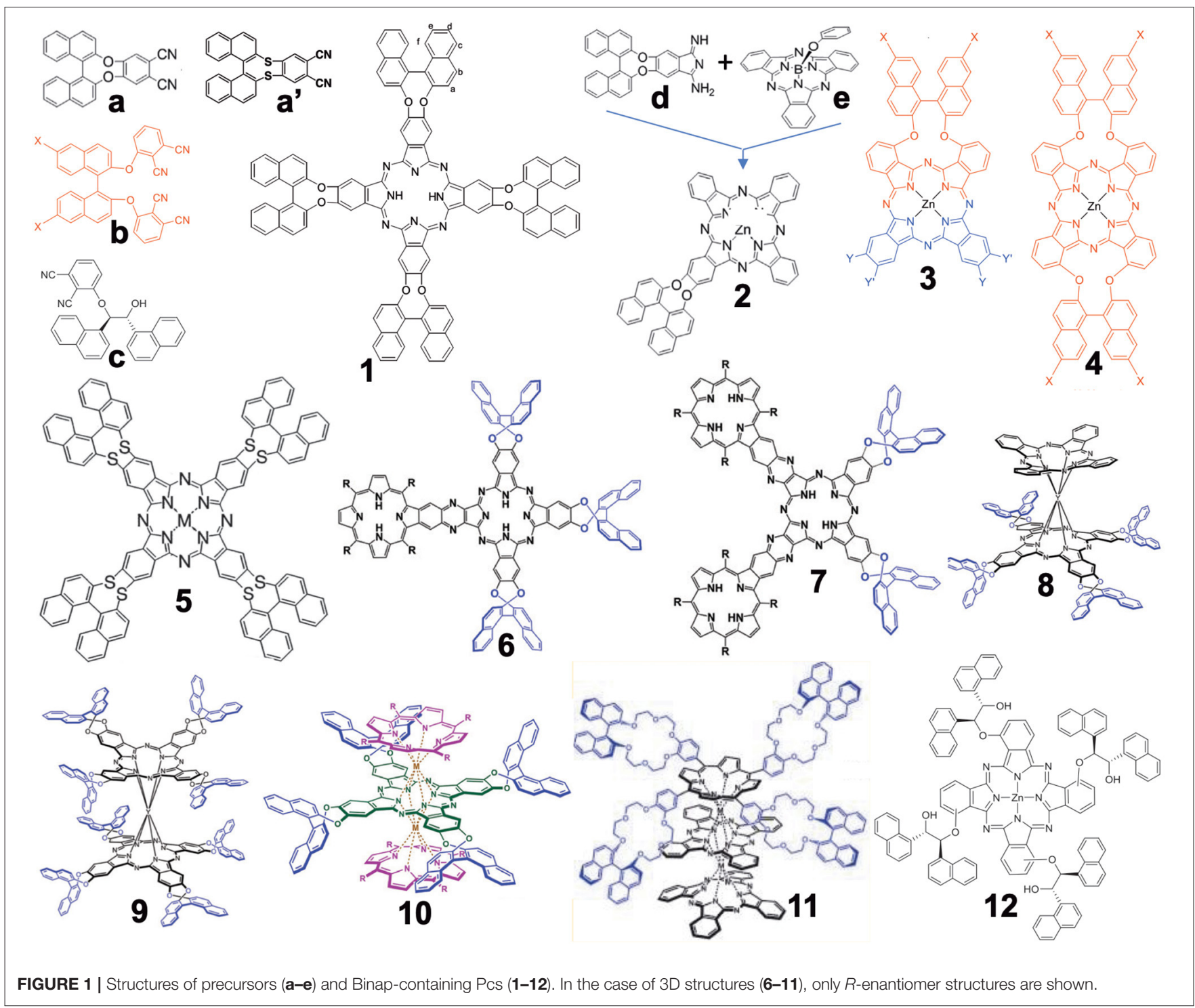


more than 300 papers have appeared on the use of this method (Claessens et al., 2002, 2014; Kobayashi, 2002). Compounds 3 and 4 containing long alkyl chains were prepared by Torres' group in order to study their aggregation (Revuelta-Maza et al., 2019). The precursor b was reported as early as 1998 as a stable phthalonitrile which does not racemize under normal Pc formation conditions (Kobayashi, 1998), so that the reaction of $\mathbf{b}$ and long-alkyl chain-containing phthalonitrile afforded Pc 3 preferentially, and reactions of only $\mathbf{b}$ produced $\mathbf{4}$ in relatively high yield.

Compounds 6 and 7 contain porphyrin units. In order to synthesize these compounds, mixed condensation between a and pyrazinonitrile fused to a trimethylphenylporphyrin was performed in the presence of lithium in refluxing pentanol, and 6 and 7 were separated after purification using column chromatography in ca. $6-10 \%$ yield (Zhang et al., 2017). Triple-decker compound 11 containing both porphyrin and two Pc units were prepared in ca. $40 \%$ yield by reacting the corresponding metal-free crowned binaphthyllinked porphyrin and substituent-free $\mathrm{H}_{2} \mathrm{Pc}$ in the presence of a rare-earth metal, $\mathrm{Mt}(\mathrm{acac})_{3} \cdot n \mathrm{H}_{2} \mathrm{O}(\mathrm{Mt}=\mathrm{Eu}, \mathrm{Y})$, in refluxing trichlorobenzene ( $\mathrm{Lu}$ et al., 2011). Although the reaction temperature was $218^{\circ}$, no racemization of the binaphthyl unit occurred.

Compound 12 was synthesized from precursor $c$ which was prepared from 3-nitrophthalonitrile and $(1 R, 2 R)$ 1,2-di(naphthalen-1-yl) ethane-1,2-diol in the presence of $\mathrm{Zn}(\mathrm{OAc})_{2} \cdot n \mathrm{H}_{2} \mathrm{O}$ and a catalytic amount of DBU (1,8-dia-zabicyclo[5.4.0]undec-7-ene) by a Turkish group (Gok et al., 2018).

\section{Spectroscopic Properties}

It is important to show at least the electronic absorption, circular dichroism (CD), and magnetic circular dichroism (MCD) spectra of representative compounds. Figure 2 shows some spectra of compounds $\mathbf{1}, \mathbf{5}, \mathbf{9}$, and $\mathbf{1 0}$. The absorption and MCD spectra of $\mathbf{1}$ are typical of those of metal-free Pcs, in that it shows four Q-band peaks and Faraday B-term MCD (Fukuda and Kobayashi, 2010). (R)- and (S)-enantiomers show mainly positive and negative $\mathrm{CD}$, respectively, similarly to $\mathbf{5}$ (Kobayashi et al., 1999a). A small negative CD trough observed at $782 \mathrm{~nm}$ for the (R)-enantiomer suggests that $\mathbf{1}$ is not completely planar. 9 is a cofacial rare-earth double decker. The interpretation of the spectra of these types of double-decker Pcs and porphyrins was already reported in 2005 (Muranaka et al., 2005). Similarly to $\mathbf{1},(R)$ - and (S)-enantiomers show positive and negative CD, respectively, associated with each absorption peak. Although the apparent absorption coefficient of the $\mathrm{Q}$ band is larger than that in the Soret region, inversely, the Soret band CD intensity is much larger than the $\mathrm{Q}$ band $\mathrm{CD}$ intensity, which is due to the energy difference in the binaphthyl absorption (ca. 220-250 nm) and the Soret (ca. 330-350 nm) or Q band (ca. $670 \mathrm{~nm})$. Here, since the induced CD intensity is proportional to $1 /\left(v_{\mathrm{N}}^{2}-v_{\mathrm{Pc}}^{2}\right)$, where $v_{\mathrm{N}}$ and $\nu_{\mathrm{Pc}}$ are the frequencies of the absorption of naphthalene and $\mathrm{Pc}$, respectively, the Soret band $\mathrm{CD}$ becomes stronger than the $\mathrm{Q}$ band CD (Kobayashi et al., 2012).

The curves in Figure 2C are both the fluorescence-detected CD (FDCD) (ca. 200-270 nm) and FD "induced" CD (FDICD) spectra (ca. $270-700 \mathrm{~nm}$ ) observed for the metal-free and zinc complexes of $\mathbf{5}$, of which the latter FDICD data are the only

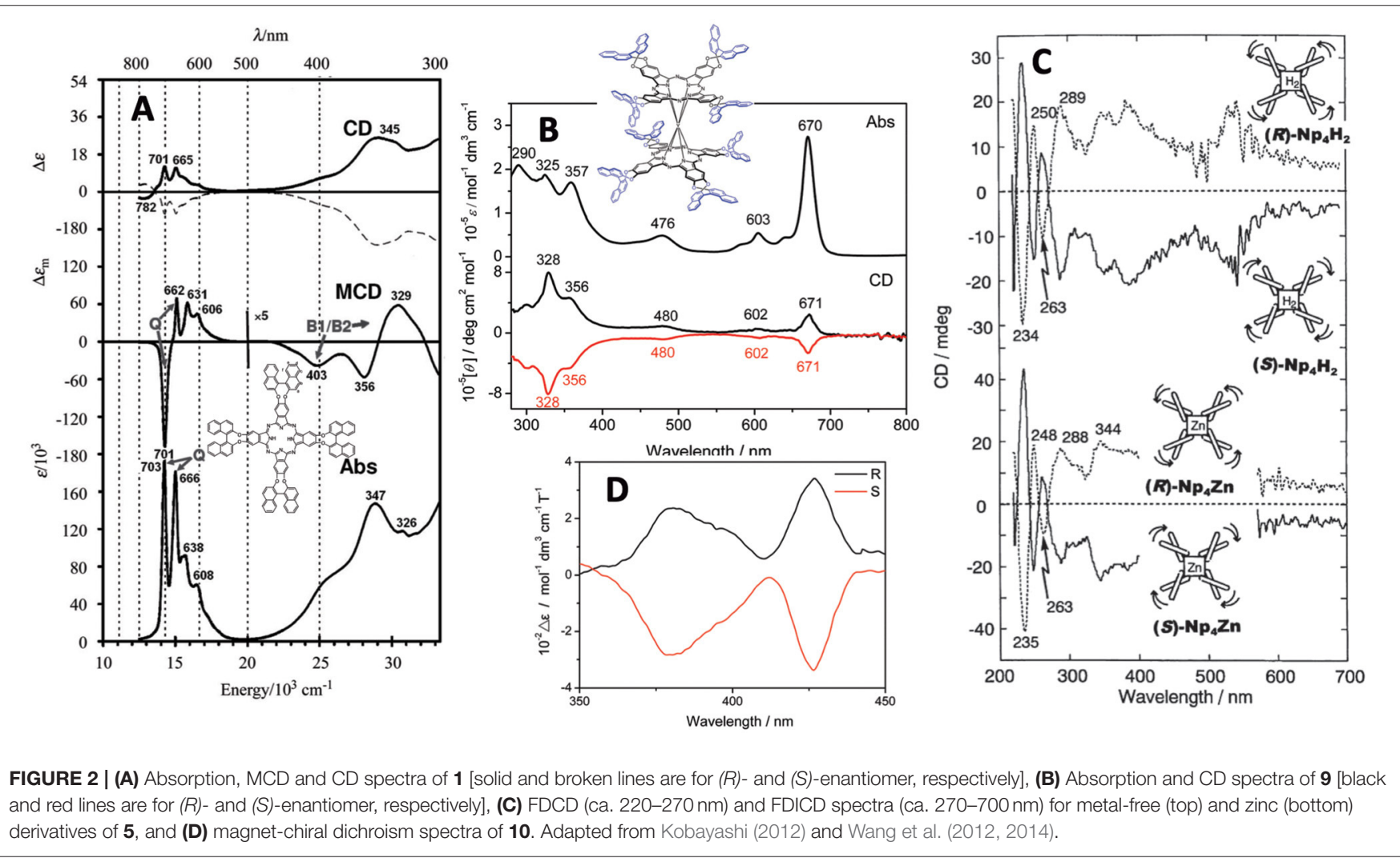


published data for any compound (Kobayashi, 2012). The FDICD signal was positive for (R)-binaphthayl linked species (lefthanded conformer), while negative for (S)-binaphthayl linked Pcs, suggesting that the $(S)$ species (right-handed conformer) absorbs right-circularly polarized light more than the left, and vice versa for the $(R)$ species (left-handed conformer).

The spectra in Figure 2D are the rare magnet-chiral dichroism spectra of $\mathbf{1 0}$ in the 360-450 $\mathrm{nm}$ region where strong ICD and MCD signs were detected. The value of $\Delta \varepsilon(=$ $10^{2} \mathrm{~mol}^{-1} \mathrm{dm}^{3} \mathrm{~cm}^{-1} \mathrm{~T}^{-1}$ ), was comparable to those reported previously in porphyrinoids (Kitagawa et al., 2011, 2012).

Comparing the absorption spectra of 6 and 7, the Q band of $\mathbf{6}$ splits, while that of $\mathbf{7}$ does not, as proven by group theory (Kobayashi and Konami, 1996). In these cases, the absorptions are roughly expressed as a summation of the spectra of porphyrin and $\mathrm{Pc}$, but the $\mathrm{Q}$ band region is mainly the contribution from the Pc moiety. Viewing from the Pc structure, $\mathbf{6}$ is mono-substituted type $\mathrm{Pc}$, while 7 is adjacent-type di-substituted Pc, so that $\mathrm{Q}$ the band of Pc 6 splits. In both cases, the (R)- and (S)-enantiomer showed mainly positive and negative $C D$, respectively. The Qband MCD of 7 is dispersion type pseudo Faraday A term, since the splitting of the $\mathrm{Q}_{\mathrm{x}}$ and $\mathrm{Q}_{\mathrm{y}}$ bands is small. The CD spectra of $\mathbf{1 1}$ are noisy, due to the long distance of the perturber (binaphthyl units) from the macrocyclic chromophore. Faraday A-term MCD curves were observed corresponding to each absorption peak, since the excited state of this type of porphyrinoid is orbitally doubly degenerate (Muranaka et al., 2005). Compound 12 was prepared only from 3-((1'R,2'R)2-hydroxy-1', 2'-dinaphtylethoxy)phthalonitrile c, and no Pc from the corresponding $\left(1^{\prime} S, 2^{\prime} S\right)$-enantiomer was reported. Its absorption spectrum is normal, similar to that of regular Pcs, and weak negative $\mathrm{CD}$ envelopes were detected associated with the $\mathrm{Q}$ and Soret bands.

\section{OPTICALLY-ACTIVE ALKYL CHAIN-CONTAINING PHTHALOCYANINES}

\section{Synthesis}

Chiral alkyl chain-containing Pcs have often been prepared in order to examine their liquid crystalline properties (Ohta et al., 2011; Basova et al., 2016). The structures of Pc compounds categorized in this group are shown in Figure 3, which are all reported from Zhang's group. As seen in the figure, all substituents contain chiral (S)-2-methylbutoxy moieties next to the Pc skeleton or at the outer end of substituent groups. The reaction of 3-nitorophthalonitrile with (S)-2-methylbutanol in the presence of $\mathrm{K}_{2} \mathrm{CO}_{3}$ produced 3- $((S)$ 2-methylbutoxy)phthalonitrile, whose cyclic tetramerization performed using lithium or in the presence of $\mathrm{Zn}(\mathrm{OAc})_{2} \cdot 2 \mathrm{H}_{2} \mathrm{O}$ or $\mathrm{Cu}(\mathrm{OAc})_{2} \cdot n \mathrm{H}_{2} \mathrm{O}$ and $\mathrm{DBU}$ produced $\mathbf{1 3}\left((S)-\mathbf{H}_{2} \mathbf{P c}-\right.$, $\mathbf{1 3}\left(\mathrm{ZnPc}-\right.$, or $\mathbf{1 3}\left(\mathrm{CuPc}\left(\alpha-\mathrm{OC}_{5} \mathrm{H}_{11}\right)_{4}\right)$, respectively (Tian et al., 2013a).

A similar reaction between (S)-4-hydroxy-4'-(2methylbutoxy)biphenyl and 4,5-dichloro-1,2-dicyanobenzene in the presence of $\mathrm{K}_{2} \mathrm{CO}_{3}$ in DMF produced 1,2-dicyano4,5-bis[(S)-4'-(2-methylbutyoxy)biphenyl]benzene, which was then tetramerized similarly, to yield octa-substituted $\mathrm{H}_{2}$ - and $\mathrm{ZnPcs}$ at $\beta$-positions, i.e., $\mathbf{1 4}\left((S)-\mathbf{H}_{2}\right.$ Pc-A) and $\mathbf{1 4}((S)-\mathrm{ZnPc}-\mathbf{A})$

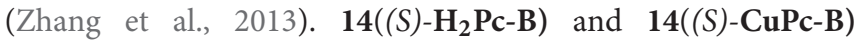
were similarly prepared using a phthalonitrile having a long alkyl chain at the 4,5-positions, which was synthesized in four steps starting from catechol (Tian et al., 2013b). $\mathbf{1 4}\left((S)-\mathbf{C u}-\right.$ and $\left.-\mathrm{CoPc}\left(\boldsymbol{\beta O C} \mathbf{C}_{5} \mathrm{H}_{11}\right)_{8}\right)$ were synthesized using 4,5-di-( $(S)$-2-methylbutoxy)phthalonitrile that was prepared by reacting (S)-2-methylbutanol with 4,5-dichlorophthalonitrile. $15\left(\mathrm{CoPc}\left(\alpha \mathrm{OC}_{5} \mathrm{H}_{11}\right)_{8}\right)$ was prepared using 3,6-di- $((S)-2$ methylbutoxy)phthalonitrile which was prepared by reaction

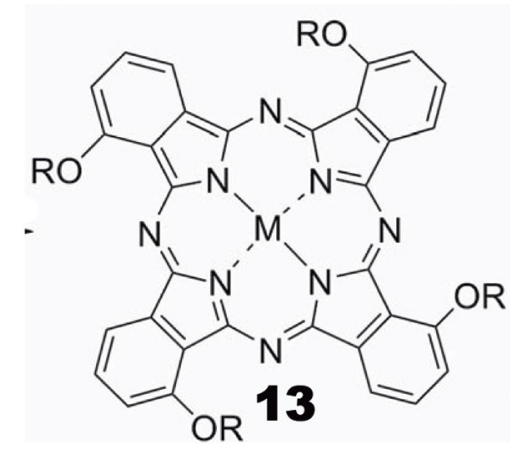

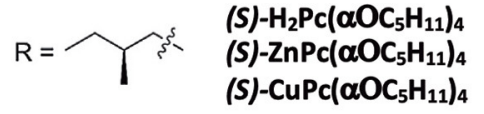

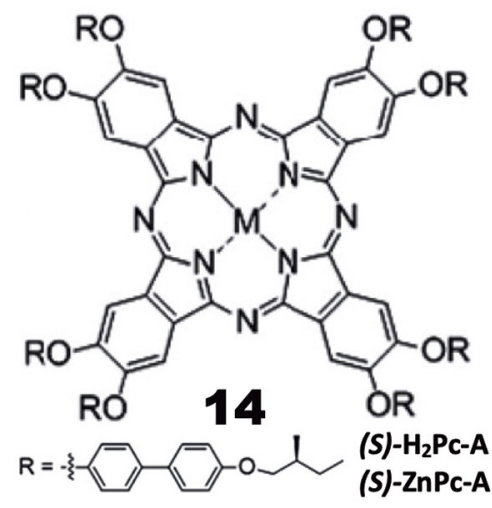

$R=-3 八 0 \sim 0 \bigcirc \begin{aligned} & (S)-\mathrm{H}_{2} \mathrm{Pc}-\mathrm{B} \\ & (\mathrm{S})-\mathrm{CuPC}-\mathrm{B}\end{aligned}$ $R=\widehat{\text { s. }} \begin{aligned} & (\mathrm{S})-\mathrm{CuPc}\left(\mathrm{\beta OC}_{5} \mathrm{H}_{11}\right)_{8} \\ & (\mathrm{~S})-\operatorname{CoPc}\left(\mathrm{\beta OC}_{5} \mathrm{H}_{11}\right)_{8}\end{aligned}$

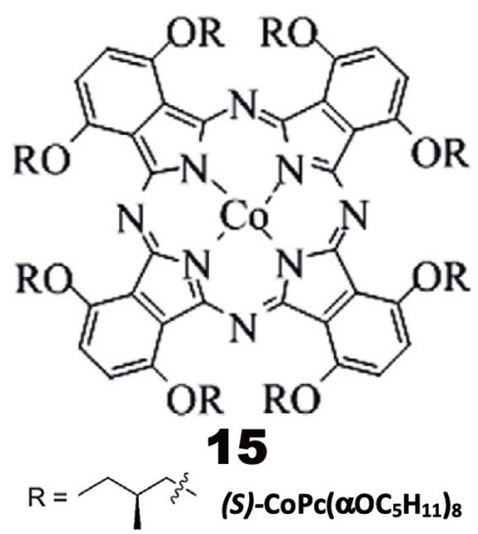

FIGURE 3 | Structures of optically-active alkyl chain-containing phthalocyanines. 
between (S)-2-methylbutanol and 3,6-dihydroxyphthalonitrile (Lin et al., 2015).

\section{Properties}

Induced CD spectra due to optically-active carbon is generally very weak (Kobayashi et al., 2012), and is not well-reproduced by theoretical calculations. Indeed, although most of the Pc compounds in Figure 3 showed weak, noisy CD signals in the Qband region, their sign is different from compound to compound, irrespective of containing only (S)-2-methylbutoxy moieties, i.e., $13\left((S)-\operatorname{MtPc}\left(\alpha \mathrm{OC}_{5} \mathrm{H}_{11}\right)_{4}\right)\left(\mathrm{Mt}=\mathrm{H}_{2}, \mathrm{Zn}, \mathrm{Cu}\right), \mathbf{1 4}((S)-$ $\left.\mathrm{CuPc}\left(\alpha \mathrm{OC}_{5} \mathrm{H}_{11}\right)_{8}\right), \quad 14\left((S)-\mathrm{H}_{2} \mathrm{Pc}-\mathrm{A}\right), \quad 14((S)-\mathrm{ZnPc}-\mathrm{A}), \quad 14((S)-$ $\mathrm{Cu}$ - and $\mathbf{1 4}\left((S)-\operatorname{CoPc}\left(\beta O \mathrm{C}_{5} \mathrm{H}_{11}\right)_{8}\right)$, exhibited a positive sign, and the intensity of $\mathbf{1 5}\left((S)-\mathrm{CoPc}\left(\alpha \mathrm{OC}_{5} \mathrm{H}_{11}\right)_{8}\right)$ is almost zero, while both $\mathbf{1 4}\left((S)-\mathbf{H}_{2}\right.$ - and $\mathbf{1 4}((S)-\mathrm{ZnPc}-\mathrm{B})$ showed a negative sign in dilute solutions where aggregation can be neglected. The absorption and CD spectra of aggregates became broader and the $\mathrm{CD}$ intensity is stronger than in solution. However, no interpretation is given. It is a pity that the authors did not try similar experiments using compounds containing $(R)-2$ methylbutoxy groups. It is interesting to examine whether the $\mathrm{CD}$ of $(R)$-enantiomers always produce signals having a mirror image relationship to those of $(S)$-enantiomers, particularly since Pc compounds containing only (S)-2-methylbutoxy groups show both positive and negative CD signs depending on the system.

Investigation of the self-assembled $\mathbf{1 3}\left((S)-\mathbf{H}_{2} \mathbf{P c}\right.$ - and $13\left((S)-\mathbf{Z n P c}\left(\alpha-\mathrm{OC}_{5} \mathbf{H}_{11}\right)_{4}\right)$ by IR and X-ray photoelectron spectroscopies (XPS), and by transmission electronic- (TEM) and scanning electronic (SEM) microscopies, revealed that the metal-free $\mathbf{1 3}\left((S)-\mathbf{H}_{2} \mathbf{P c}\left(\alpha-\mathbf{O C}_{5} \mathbf{H}_{11}\right)_{4}\right)$ gets together to form a nanocube, while its zinc derivative, $13((S)-\mathrm{ZnPc}(\alpha-$ $\left.\mathrm{OC}_{5} \mathrm{H}_{11}\right)_{4}$, gets together to produce assembly of helical nanobelts, which implies that the morphology and handedness of the self-assembled nano-structures are affected by metal coordination (Tian et al., 2013a). Similarly, with respect to 14((S)- $\mathrm{H}_{2}$ Pc-A) and $\mathbf{1 4}((\mathrm{S})-\mathrm{ZnPc}-\mathrm{A})$, it was found that the molecular packing in the nano-structures is influenced by the metal-coordination bond, resulting in nano-structured assembly with different morphologies, ranging from nanosheet for $\mathbf{1 4}\left((S)-\mathbf{H}_{2} \mathbf{P c}-\mathbf{A}\right)$ to helical nanofibers for $\mathbf{1 4}((S)-\mathrm{ZnPc}-\mathbf{A})$. In the cases of $\mathbf{1 4}\left((S)-\mathrm{H}_{2} \mathrm{Pc}-\mathrm{B}\right)$ and $\mathbf{1 4}((S)-\mathrm{CuPc}-\mathrm{B})$, the former $\mathrm{H}_{2} \mathrm{Pc}$ self-assembles into clockwise right-handed screw-like fibers (ca. $10 \mu \mathrm{m}$ length, $6 \mu \mathrm{m}$ width, and $1.5 \mu \mathrm{m}$ helical pitch), while the latter $\mathrm{CuPc}$ self-assembly into anti-clockwise left-handed aggregates of fibers (ca. $25 \mu \mathrm{m}$ length, $1 \mu \mathrm{m}$ width, and $0.7 \mu \mathrm{m}$ helical pitch) (Tian et al., 2013b). In the mesophase, $\mathbf{1 5}\left((S)-\mathbf{C u P c}\left(\alpha \mathbf{O C}_{5} \mathbf{H}_{11}\right)_{4}\right)$ gathers into rectangular columnar liquid crystals with anti-clockwise fan textured structure. However, from $14\left((S)-\mathbf{C u P c}\left(\beta \mathrm{OC}_{5} \mathrm{H}_{11}\right)_{8}\right)$, hexagonal columnar liquid crystals with well-ordered, rare, clockwise spherulites were produced. The helical self-assembly and non-linear optical properties of $(S)-\mathrm{CoPc}\left(\alpha \mathrm{OC}_{5} \mathrm{H}_{11}\right)_{8}$ were comparatively investigated with its analog having the same chiral moieties linked by substituents at $\beta$-positions, i.e., $\mathbf{1 5}\left((S)-\mathbf{C o P c}\left(\boldsymbol{\beta O C}_{\mathbf{5}} \mathbf{H}_{11}\right)_{\mathbf{8}}\right)$ (Lin et al., 2015). Although these two compounds have the identical chiral functional group, they showed different $\mathrm{CD}$ signals in the $\mathrm{Q}$ absorption region of the corresponding complex, and gathered into different morphologies. At the initial stage, they got together into clockwise ribbon-like structures, while in the further later stage of assembly, they formed either clockwise or anti-clockwise fibrous structures.

\section{CHIRAL SUBPHTHALOCYANINE SYSTEMS}

General Pcs consist of four isoindoline units and are almost flat, but subphthalocyanine (SubPc) is a Pc congener consisting of three isoindoline units and boron coordinated with an axial ligand (Figure 4). Accordingly, it has a cone-shaped structure and blue-shifted Soret and Q bands. As a chiral SubPc, peripherally chiral binaphthyl-linked SubPc $\mathbf{1 6}$ has been known since 2014 (Zhao et al., 2014). The starting materials are $(S)$ - and $(R)$-a in Figure 1. By refluxing these in the presence of $\mathrm{BCl}_{3}$ in 1,2,4-trichlorobenzene, the target SubPcs 16 were obtained in ca. $33 \%$ yield. Even the ${ }^{1} \mathrm{H}-\mathrm{NMR}$ spectra are interesting in that the ring-current effect is different between the endo and exo sides (the ring current of the SubPc ring is stronger in the concave side of the bowl than the convex side) (Shimizu et al., 2012). Thus, since one binaphthyl unit lies on the exo side while the other lies on the endo side, the ${ }^{1} \mathrm{H}$ proton signals of binaphthyl appeared far away from each other.

Subnaphthalocyanine (SubNc) can be obtained by reacting naphthalonitrile in the presence of a boron compound, such as
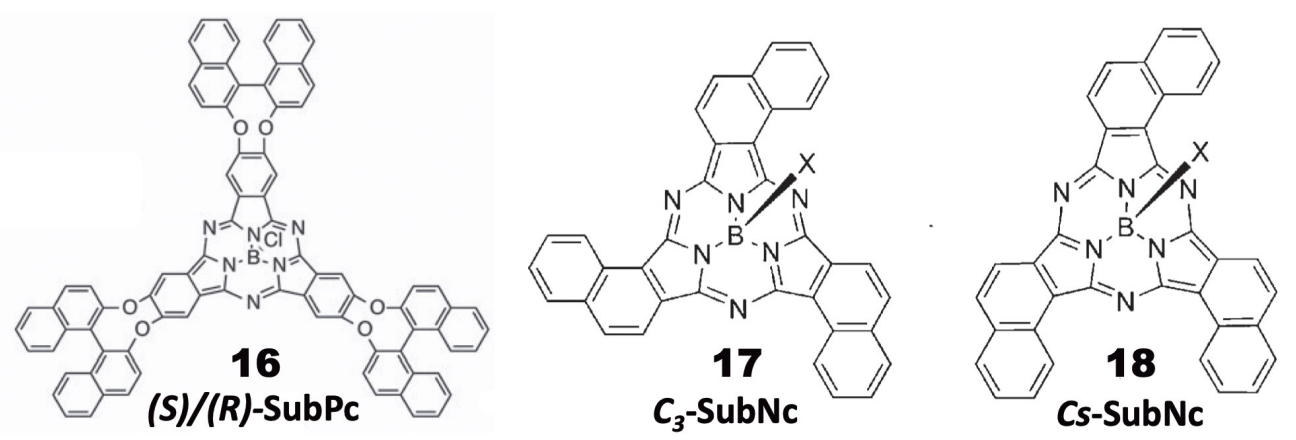

FIGURE 4 | Structures of (S)- or (R)-binaphthyl-linked SubPc $\mathbf{1 6}$ and $C_{3^{-}} \mathbf{1 7}$ and $C_{S^{-}}$subnaphthalocyanine (SubNc) 18. 
$\mathrm{BCl}_{3}$ in a solvent, such as dimethylbenzene or trimethylbenzene (Kobayashi, 2002). If 1,2-dicyanonaphthalonitrile is used as a starting material, the product is a mixture of inherently chiral $C_{3}$-SubNc 17 and $C_{\boldsymbol{s}}$-SubNc 18 isomers, which can be separated by column chromatography. Further, each isomer can be resolved, by using chiral columns, to clockwise and anticlockwise enantiomers viewing from the axial ligand (Shimizu et al., 2011).

Figure 5 shows the absorption, fluorescence, CD and MCD spectra of SubPc with chiral binaphthyl-linked SubPc and $\boldsymbol{C}_{\mathbf{3}^{-}}$ SubNc 17. The Q and Soret bands of SubPc generally appear at 570 and $280-300 \mathrm{~nm}$, blue-shifted compared with those of Pcs [ca. 650-680 and 330-350 nm, respectively (Fukuda and Kobayashi, 2010)]. The Q-band MCD signals are mainly a contribution of Faraday C terms, since the SubPc chromophore itself can be approximated as having $C_{3 v}$ symmetry, i.e., the first excited state is doubly degenerate. The enantiomer with $(R)$ - and (S)-chirality in the binaphthyl moiety produced plus and minus CD signs, respectively, over the whole window region. The angle between the two naphthyl units in binaphthyl is about 66 degrees, and the sign and intensity of CD can be reasonably explained similarly to the chiral binaphthyl-linked Pc systems (Kobayashi et al., 1999a), although the SubPc system might be slightly more difficult due to its bowl-shaped structure. Nevertheless, molecular orbital calculations using the TD-DFT method succeeded in reproducing the minus $\mathrm{CD}$ signals associated with the $\mathrm{Q}$ and Soret bands of the (S)-SubPc 16 compound. The absorption spectrum (particularly wavelengths) of 1,2-SubNc does not differ significantly from that of SubPc, since outer benzene rings are not fused in a radial direction, viewing from the central boron of the molecule (Kobayashi and Konami, 1996). The two peaks on the longer-wavelength side of the Soret band are characteristic of naphthalocyanine derivatives (Kobayashi, 2002). Although not shown in this review, the absorption spectrum of the $C_{s}$-isomer 18 is almost identical to that of the $C_{3}$-isomer 17 in Figure 5B, so that the MCD spectra of the two isomers also have very similar band shape to each other. However, the CD intensity of these isomers are quite different, where that of the $C_{3}$-isomer $\mathbf{1 7}$ is about three times stronger than for the $C_{s}$-isomer $\mathbf{1 8}$. Theoretically, the CD intensity (rotational strength) is directly proportionate to the product of the transition electric moment $(\mu)$ and the transition magnetic moment $(m)$, i.e., $\mu m$, whilst the absorption intensity (oscillator strength) is proportionate to the square of $\mu$, i.e., $\mu^{2}$ (Kobayashi et al., 2012). The fact that the absorption spectra of the $C_{3}-\mathbf{1 7}$ and $C_{s}$-isomers $\mathbf{1 8}$ are almost identical means that the $\mu$ values of these two compounds are also considered almost identical. Therefore, we can attribute the CD intensity difference between the $C_{3}-\mathbf{1 7}$ and $C_{s}$-isomers 18 to $m$. The transition magnetic moment $m$ is generated along the $\mathrm{z}$-direction when charge is rotated in the $\mathrm{x}-\mathrm{y}$ plane. If we compare the geometrical structures of the $C_{3}-17$ and $C_{s}$-isomers 18 of $1,2-$ SubNcs, it sounds feasible that the net $m$ values of the $C_{3}$-isomer 17 are lessened to one-third in $C_{s}$-isomer 18 by one oppositely-arranged naphthalene moiety in the latter isomer. Thus, this is a very rare but exemplary system which certifies that the magnitude of $m$ is really parallels the rotation of charge. The absolute structure of $C_{3}$-SubNcs 17 elucidated by X-ray crystallography led to a comprehensive understanding of the structure-chirality relationship of 1,2-SubNcs; i.e., the minus CD signals in the Q-band region indicate a molecular structure where
A

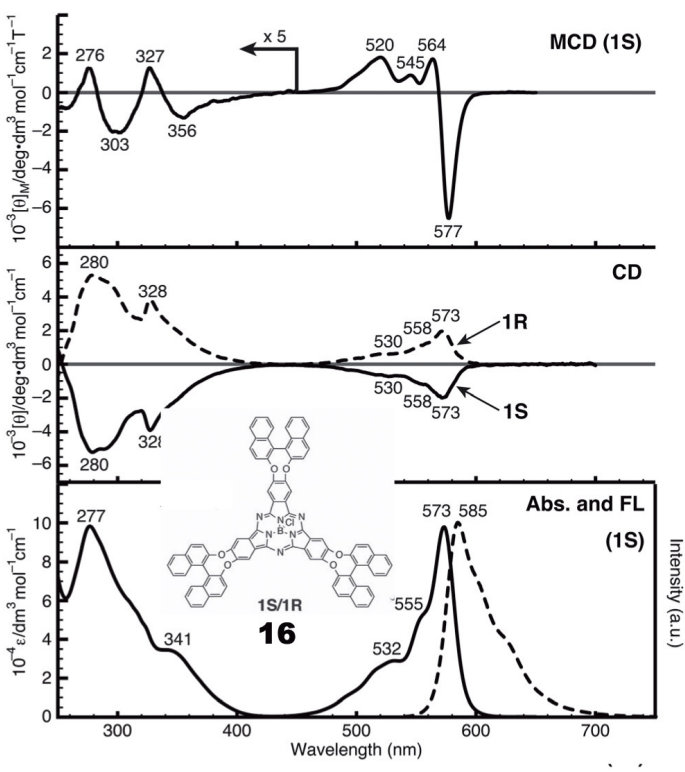

B

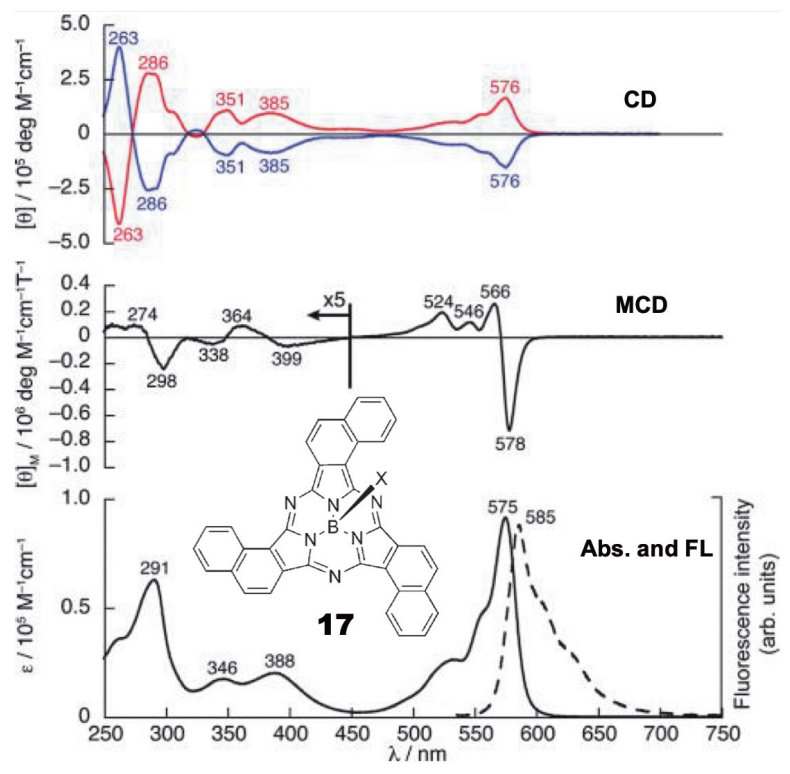

FIGURE 5 | Electronic absorption, fluorescence, $C D$, and MCD spectra of (A) chiral binaphthyl-linked SubPc 16, and (B) $C_{3}-S u b N c$ 17. In the CD of $C_{3}-S u b N c$ 17, the red and blue lines are from enantiomers whose naphthalene rings are arranged anti-clockwise and clockwise, respectively. Adapted from Shimizu et al. (2011) and Zhao et al. (2014). 
the naphthalene moieties are arranged right-handed, whilst the plus CD signals in the same region indicate an left-handed arrangement viewing from the axial ligand side.

\section{OPTICALLY-ACTIVE SYSTEMS DUE TO COORDINATION OF CHIRAL LIGANDS}

Many chromophores are not optically active, but by coordination of an extraneous chiral ligand, the system becomes optically active. Zhang et al. (2011) added equimolar amounts of chiral diamine to tetracarboxyphthalocyanine metal complexes $(\mathrm{MtTCPc}, \mathrm{Mt}=\mathrm{Cu}, \mathrm{Ni})$ in $\mathrm{DMSO} / \mathrm{CHCl}_{3}$ mixed solvent, and succeeded in inducing $\mathrm{CD}$ signals in the region of the absorption spectrum. The diamines used were: $(1 R, 2 R)-(-)-$ and $(1 S, 2 S)-(+)-1,2$-diaminocyclohexane, $(1 R, 2 R)-(+)-$ and $(1 S, 2 S)-(+)-1,2$-diphenyl-1,2-ethylenediamine (DPEA), $(R)$ $1,1^{\prime}$ - and $(S)-1,1^{\prime}$-binaphthyl-2,2'-diamine, in addition to $(R)$-1-phenylethanamine, $(R)$-1-(naphthalene-1-yl)-ethanamine, and (-)-sparteine. The CD signal induced by adding $(1 R, 2 R)$ and $(1 S, 2 S)$-diamine exhibited a mirror-symmetry structure in relation to the signal intensity $=$ zero line, and its intensity was largest when the amount of diamine was equimolar to that of MtTCPc. By increasing $\mathrm{CHCl}_{3}$ (poor solvent) in DMSO (good solvent) from $1: 1(\mathrm{v} / \mathrm{v})$, the absorption spectrum changed to that of cofacial aggregates, and concomitantly the CD intensity decreased. Surprisingly, in the presence of $(R)$ - or (S)-DPEA, MtTCPc $(\mathrm{M}=\mathrm{Ni}, \mathrm{Cu})$ showed no significant $\mathrm{CD}$ and $\mathrm{UV} / \mathrm{Vis}$ spectral changes before and after the addition of an equimolar amount of the corresponding antipode ((S)- or (R)-DPEA, totally, $R / S$ or $S / R=1: 1)$, implying a very quick self-gathering ability of MtTCPc that produces highly stable optically-active MtTCPc $\pi-\pi$ stacks whose chirality is immobilized firmly.

The aggregate's morphology of supramolecular MtTCPc was studied by high resolution TEM. Samples on a carbon-coated copper minigrid were prepared by casting a drop of MtTCPc solution onto its surface. This showed that supramolecular MtTCPcs $(\mathrm{M}=\mathrm{Ni}, \mathrm{Cu})$ adopted an entangled structure composed of nano-structural fibers of about $10 \mathrm{~nm}$ diameter and 150-700 nm length.

\section{CHIRAL CONGENERS OF PHTHALOCYANINE-RELATED COMPOUNDS}

Four papers reporting various types of hemiporphyrazine (Figure 6) were found in this category, and they are introduced in chronological order. anti-19 and syn-19 were prepared at a ratio of ca. 1:1 by heating an equimolar amount of isoindolediimine

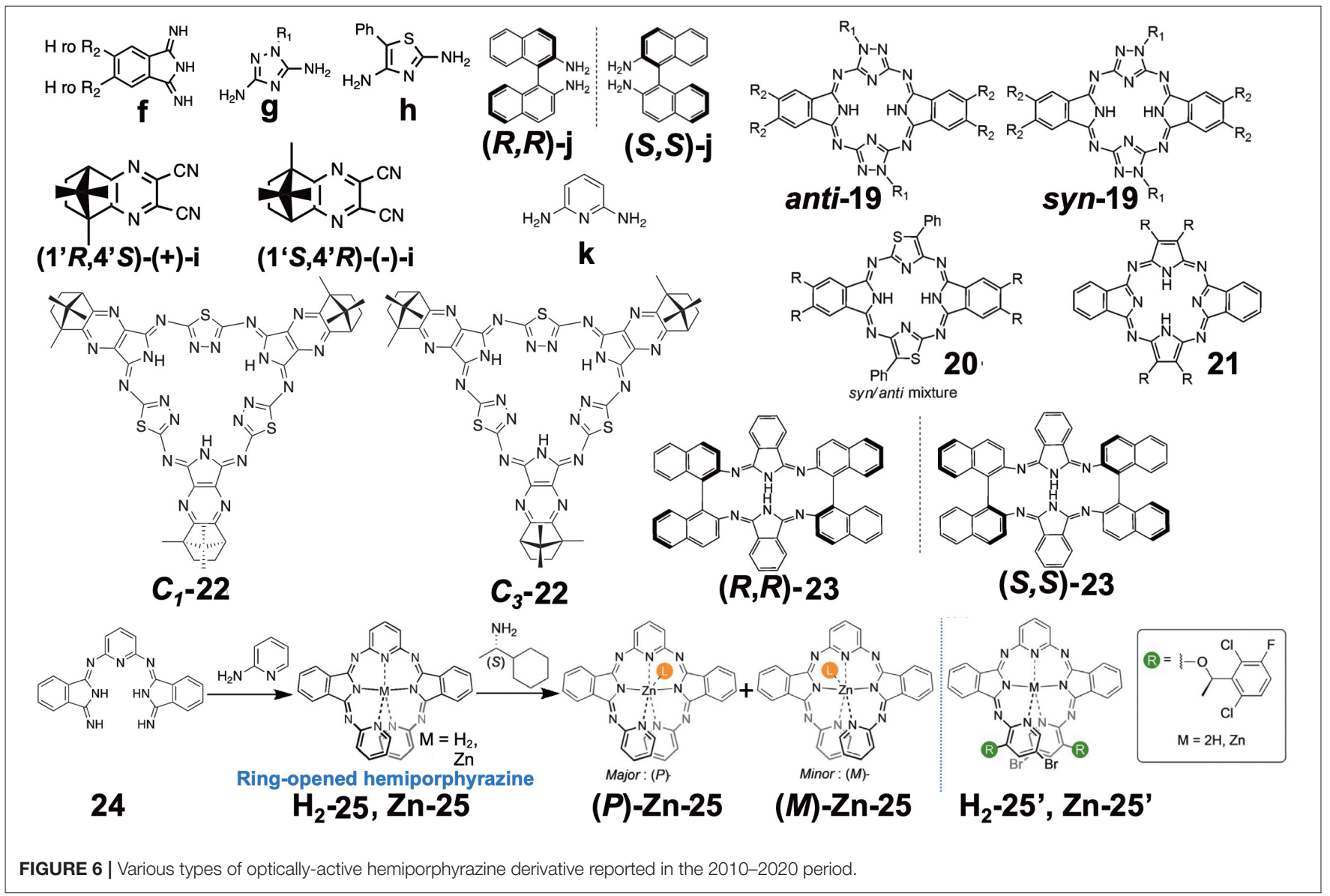


f and triazole diamine $\mathbf{g}$ (Muranaka et al., 2014). anti and syn structures were confirmed from ${ }^{1} \mathrm{H}-\mathrm{NMR}$ and IR spectra: The pyrrole proton signal appeared at around $15 \mathrm{ppm}$, but as a singlet for $\boldsymbol{a n t i - 1 9}$ and two singlets for syn-19, and in the powder state, the former showed a single $\mathrm{NH}$ stretching vibration at 3,298 $\mathrm{cm}^{-1}$, while two peaks were detected for the latter at 3,363 and $3,291 \mathrm{~cm}^{-1}$. Insertion of VO to anti-19 was performed in order to obtain intrinsically-chiral triazolehemiporphyrazine (Kobayashi et al., 2009), whose resolution was achieved by high-performance liquid chromatography. In order to compare the properties of 19 with those of congeners, 20 and 21 were synthesized from isoindolediimine $\mathbf{f}$ and thiazole diamine $\mathbf{h}$ in 2-ethoxyethanol at $135^{\circ} \mathrm{C}$, and isoindolediimine $\mathbf{f}$ and 4,5 -dicyano-4-octene in the presence of magnesium in butanol at boiling temperature, respectively. Pyrrole proton ${ }^{1} \mathrm{H}$ NMR signals of $\mathbf{2 0}$ and $\mathbf{2 1}$ were observed at ca. 13.6-14.2 and -1.93 ppm, respectively, suggesting that $\mathbf{2 0}$ is anti-aromatic while $\mathbf{2 1}$ is aromatic.

Molecular orbitals (MOs) of these molecules were calculated, and it was found that the anti-forms of $\mathbf{1 9}$ and $\mathbf{2 0}$ have HOMO and LUMO with five nodal patterns, while those of $\mathbf{2 1}$ have four and five nodal patterns, respectively. Obviously, the nodal patterns of the HOMO-1, HOMO, and LUMO of the anti-19 and 20 were respectively in connection with the HOMO, LUMO, and LUMO +1 of the $18 \pi$-electron dibenzotetraazaporphyrin 21 . The LUMO and HOMO of $\mathbf{1 9}$ and $\mathbf{2 0}$ are derived from a pair of degenerate LUMOs of the $18 \pi$-electron perimeter model, while from one of the degenerate HOMOs, the HOMO-1 is derived. Accordingly, together with the pyrrole proton ${ }^{1} \mathrm{H} \mathrm{NMR}$ data at very low field, 19 and 20 were judged to be $20 \pi$ antiaromatic $[4 n \pi]$-electron systems. This kind of system can be analyzed using Michl's perimeter model (Fleischhauer et al., 2000, 2004, 2005; Muranaka et al., 2009). Figure 7A shows the experimental and calculated absorption spectra of anti-19 and 21. The spectral pattern of $\mathbf{2 1}$ retains characteristic features of a low-symmetrical tetraazaporphyrin with $D_{2 h}$ symmetry
(Kobayashi and Konami, 1996; Kobayashi, 2002), showing two prominent, split Q envelopes with coupled Faraday B-terms in the visible region (not shown). anti-19, on the other hand, revealed a weak absorption band with a pronounced vibronic progression in ca. $400-600 \mathrm{~nm}$ region, followed by stronger bands in the UV region of $<400 \mathrm{~nm}$. If we pay attention to the HOMO-LUMO transition, it is an intrashell $\Delta \mathrm{M}_{\mathrm{L}}=0$ forbidden transition for anti-19 and an $\Delta \mathrm{M}_{\mathrm{L}}= \pm 1$ allowed transition for 21, so that the longest wavelength region of anti-19 is very weak, while $\mathbf{2 1}$ has some intensity. Indeed, as seen in Figure 7B, the HOMO-LUMO transition accompanies a rotation of charge for a $20 \pi$ system (magnetic dipole allowed), but a translation of charge for 18 a $\pi$ system (electric dipole allowed). The spectra of two enantiomers of the VO complex of anti-19 are collected in Figure 7C. Most notably, a large g-factor associated with the electric dipole forbidden band in the 400-650 $\mathrm{nm}$ region was detected. The value of $g$-factor associated with the lowest-energy $S$ band at ca. $615-620 \mathrm{~nm}$ was larger than 0.01 , in accord with the rotation of charge produced by intrashell forbidden transitions. This was the first report of unambiguous spectral fact that cyclic $[4 n \pi]$-electron molecules have indeed a large transition magnetic dipole moment in the region of the lowest $\pi-\pi^{*}$ transition with forbidden character. The g-factor spectrum ends at ca. $420 \mathrm{~nm}$, where the electric dipole allowed transitions start to appear.

Filatov et al. reported the so-called $3+3$ compound 22 in

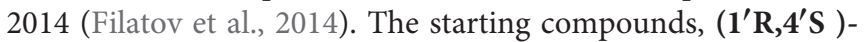
$(+)$-i and $\left(\mathbf{1}^{\prime} \mathbf{S}, \mathbf{4}^{\prime} \mathbf{R}\right)-(-)$-i were synthesized by reacting (1S)$(+)$ - or $(1 R)-(-)$-camphorquinone and diaminomaleonitrile in acetic acid at $50^{\circ} \mathrm{C}$ (Kobayashi and Nevin, 1998). Compound 22 was obtained by heating $\left(\mathbf{1}^{\prime} \mathbf{R}, \mathbf{4}^{\prime} \mathbf{S}\right)-(+)-\mathbf{i}$ and $\left(\mathbf{1}^{\prime} \mathbf{S}, \mathbf{4}^{\prime} \mathbf{R}\right)-(-)-\mathbf{i}$ together with 2,5-diamino-1,3,4-thiadiazole in either butanol in the presence of $\mathrm{CH}_{3} \mathrm{ONa}$ at ca. $100^{\circ} \mathrm{C}$ (yield $10 \%$ ) or in ethylene glycol in the absence of $\mathrm{CH}_{3} \mathrm{ONa}$ at refluxing temperature (yield $30 \%)$. Separation of $C_{1}$ and $C_{3}$ symmetry regioisomers was carried out using chiral columns. The ratio of ragioisomer, $C_{1}: C_{3}$
A

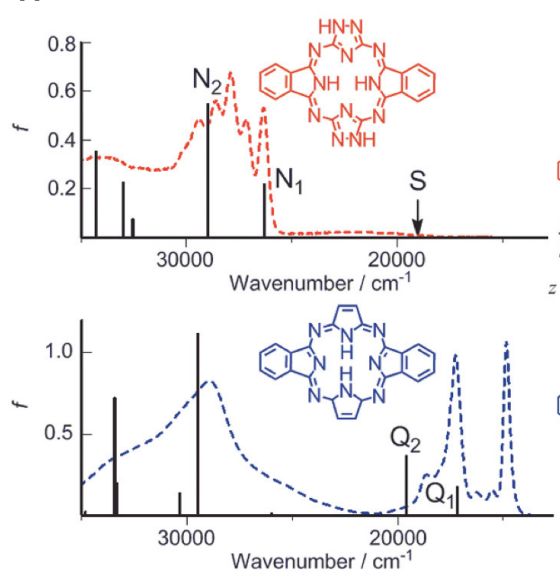

B

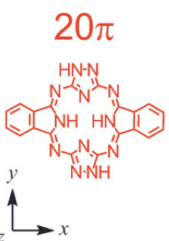

$18 \pi$

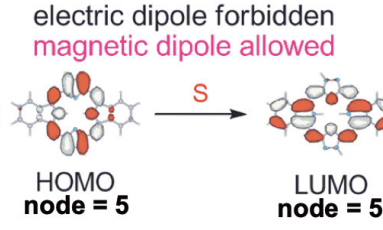

electric dipole allowed magnetic dipole forbidden
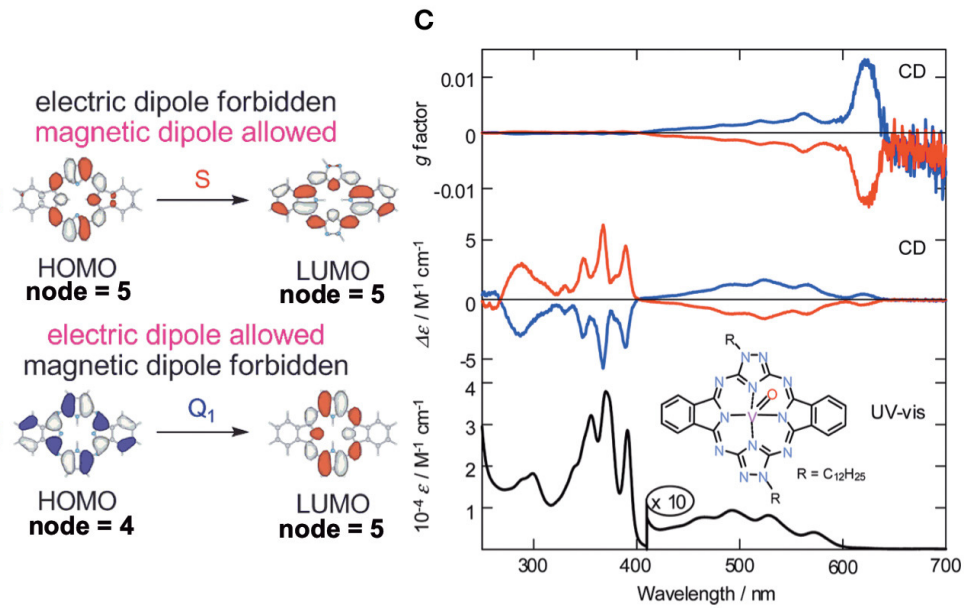

FIGURE 7 | (A) Electronic absorption spectra of anti-19 (top) and 21 (bottom), together with calculated absorption spectra. (B) HOMO and LUMO of $20 \pi-$ (top) and $18 \pi$ porphyrinoid systems (bottom). (C) Electronic absorption, CD, and CD (anisotropy g factor profile) spectra of the VO complex of anti-19. According to the theoretical calculations, the blue lines correspond to data of the anti-clockwise enantiomer whose structure is drawn inside. Adapted from Muranaka et al. (2014). 
was 57:43 for the reaction in butanol and 76:24 in ethylene glycol. In ${ }^{1} \mathrm{H}$ NMR spectra, the pyrrole $\mathrm{NH}$ signal of the $C_{3}$ isomer appeared as a singlet at $12.44 \mathrm{ppm}$, and as three singlets at $12.45,12.43$, and $12.42 \mathrm{ppm}$ for the $C_{1}$ isomer, confirming an insignificant, if any, diatomic ring current.

Figure 8A shows the absorption and CD spectra of 22. Absorption peaks appeared at 515, 474, 421, and $399 \mathrm{~nm}$, of which two peaks at longer wavelength are weak, while those at shorter wavelength are intense. According to MO calculations recently performed, these are $30 \pi$-electron, $4 n+2$ aromatic systems (Bacilla et al., 2020). Both the HOMO and LUMO are doubly degenerate, so that these are grouped into "double-soft chromophore" systems (Michl, 1978a,b,c; Michl, 1980). The two weak bands at longer wavelength correspond to transitions from $\mathrm{M}_{\mathrm{L}}=-7$ to +8 and 7 to -8 (i.e., $\Delta \mathrm{M}_{\mathrm{L}}= \pm 15$ ) transitions with forbidden character, whereas the intense bands in the ca. $380-440 \mathrm{~nm}$ correspond to allowed transitions with $\Delta \mathrm{M}_{\mathrm{L}}=$ \pm 1 . Concerning the $\mathrm{CD}$ spectra of $\mathrm{C}_{3}(S)$ - and $\mathrm{C}_{3}-(\boldsymbol{R})-22$ which

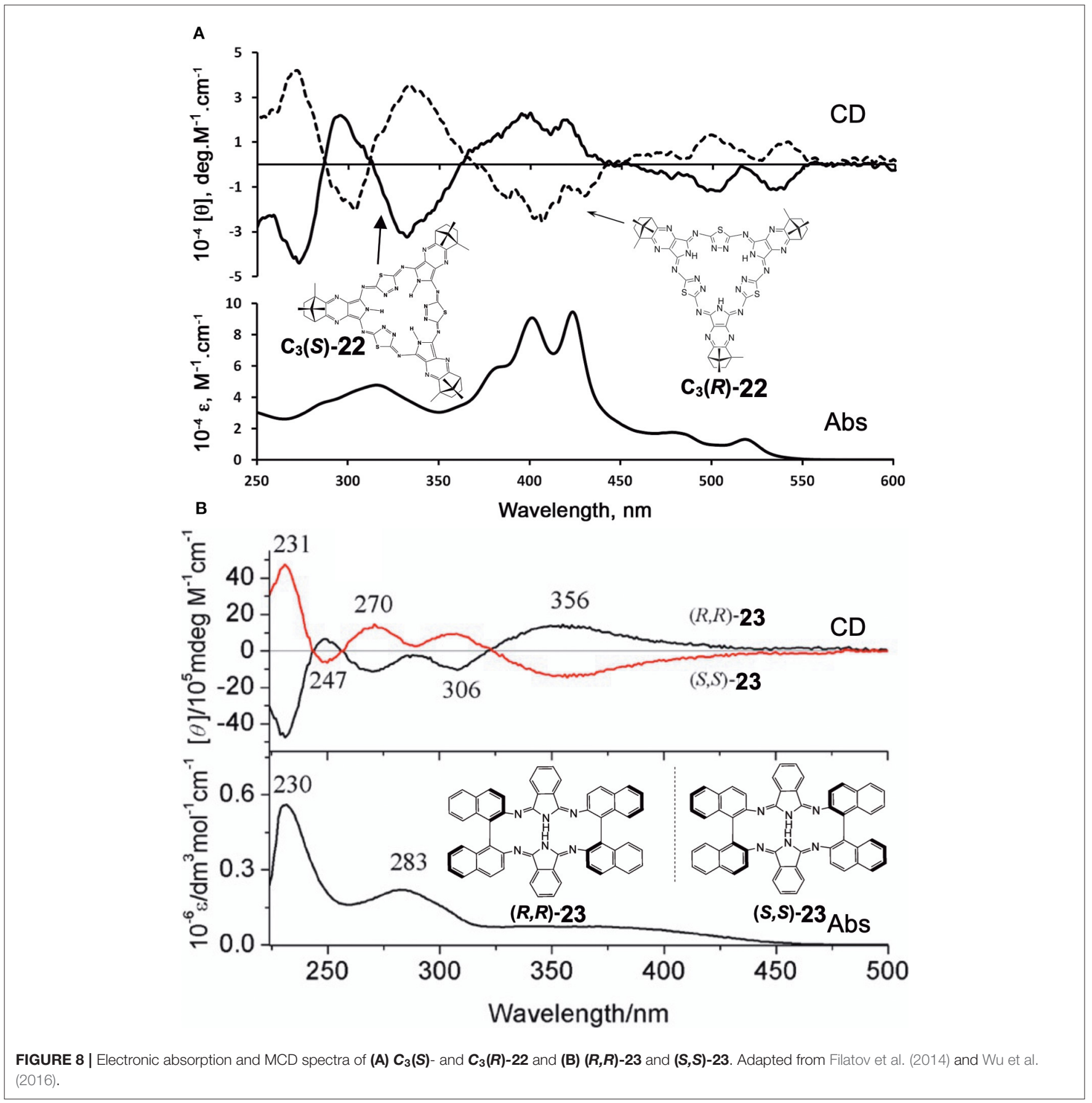


exhibit a mirror-symmetry pattern in relation to the $[\theta]=0$ line, no interpretation was attempted. Since CD in this system is generated only by optically-active carbons, its shape and intensity cannot be explained at least using the concept of CD (Kobayashi et al., 2012).

Shen et al. reported compound 23, which is a kind of hemiporphyrazine that was prepared via core modification of the macrocycle adopting an intrinsically chiral ring molecule as a part of the inner perimeter of the macrocycle (Wu et al., 2016). A condensation reaction of enantiopure chiral diamine, $(\boldsymbol{R}, \boldsymbol{R})$-j or $(S, S)$-j and isoindolediimine $\mathbf{f}$ was performed in $n$ butanol at $150^{\circ} \mathrm{C}$ for $12 \mathrm{~h}$ to give the $(\boldsymbol{R}, \boldsymbol{R})-23$ and $(\boldsymbol{S}, \boldsymbol{S})-23$ target compounds as yellow solids in ca. $3-7 \%$ yield. Although their mass and ${ }^{1} \mathrm{H}$ NMR data were in accordance with the structure shown in Figure 8, single crystal X-ray analysis further confirmed the structure of $(S, S)-23$, where the two naphthyl moieties lie around a pseudo $C_{2}$ axis and are inflexible, with an angle of ca. 85 degrees. The two isoindole moieties at opposite positions lie parallel to each other forming a kite-like conformation, so that the two nitrogen atoms in the isoindoline moiety point in the same direction (Figure 9). Thus, although previously reported himiporphyrazines have roughly planar structures, in compounds $\mathbf{2 3}$, all constituting chromophores are quite strongly deviated from the inner perimeter plane, but still exhibit absorption bands in the longer-wavelength region

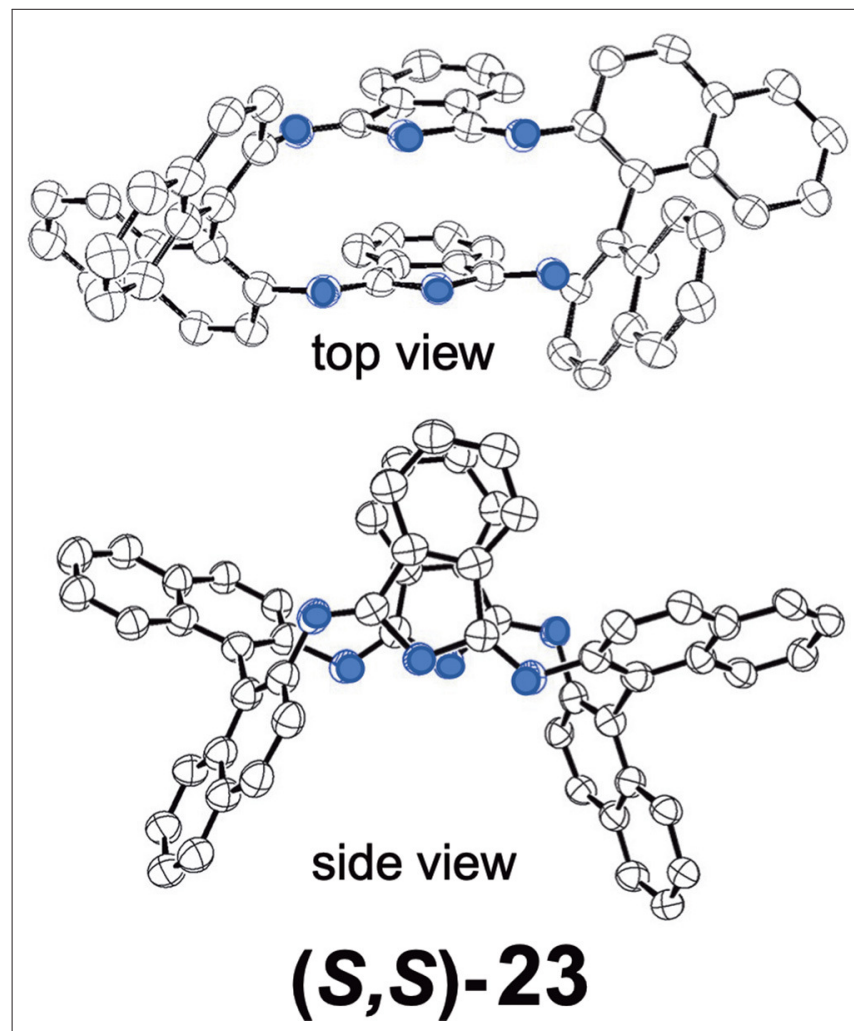

FIGURE 9 | X-ray crystal structure of $\mathbf{( S , S ) - 2 3 , ~ t o p ~ v i e w ~ a n d ~ s i d e ~ v i e w . ~}$ Adapted from Wu et al. (2016). Blue circles indicate nitrogen. (ca. 260-500 nm) that the constituting chromophore units do not show (Figure 8B). Here, in the absorption spectra, a broad intense band is seen at $283 \mathrm{~nm}$, in addition to a weaker band envelope in the $325-500 \mathrm{~nm}$ region, which is in agreement with what is generally observed for non-aromatic hemiporphyrazines. $(\boldsymbol{R}, \boldsymbol{R})-\mathbf{2 3}$ and $(\boldsymbol{S}, \boldsymbol{S})-\mathbf{2 3}$ molecules contain 18 atoms and $20-\pi$ electrons along their inner perimeter, so the authors inferred that a Mobius strip type structure could conceivably result in Mobius aromaticity. Since the isoindoline and binaphthyl moieties are severely deviated from planarity of the macrocycle, the calculated frontier $\pi$ MOs of $\mathbf{2 3}$ were predicted to be significantly localized on either the $1,1^{\prime}$-binaphthyl or isoindoline moieties, so that the spectral bands could not be easily assigned using Michl's 4N perimeter model (Howeler et al., 1998; Fleischhauer et al., 2000, 2004, 2005). Nevertheless, both the CD and absorption spectra predicted by TD-DFT calculations on the $\mathrm{X}$-ray structure of $(S, S)-23$, were in close agreement with those recorded experimentally.

Muranaka and Uchiyama et al. recently reported ringopened helical hemiporphyrazines, $\mathbf{H}_{\mathbf{2}}-\mathbf{2 5}$ and $\mathbf{Z n - 2 5}$, exhibiting circularly-polarized luminescence (CPL) (Tanaka et al., 2020). CPL-active compounds have attracted the attention of scientists, not only due to purely scientific interest, but also due to their potential applications. In order to obtain strong CPL signals accompanying a high luminescence dissymmetry factor ( $g_{\text {lum }}$ ), it is important to design molecules with a large transition magnetic dipole moment $(\mathrm{m})$ compared to the transition electric dipole moment $(\mu)$. Since many fluorescent organic molecules have a small $m$ and large $\mu$ for the $S_{1}-S_{0}$ transition, their glum is low ( $g_{\text {lum }}=10^{-5}-10^{-3}$ ). This is quite different from the $f-f$ transition in lanthanide metal complexes and the $\pi^{*}-n\left(S_{1}-S_{0}\right)$ transition in carbonyl-containing compounds, since they have an almost zero $\mu$ and a large $m$ (Riehl and Richardson, 1986; Lunkley et al., 2008). The latter case led to a relatively high luminescence dissymmetry factor ( $\left.g_{1 u m}=10^{-3}-10^{0}\right)$, but unfortunately in these systems, the emission quantum yield is very low due to the very small $\mu$. If we design hemiporphyrazine which is considered to be a $20 \pi$ system, the absorption at the longest wavelength accompanies rotation of charge, as shown in Figure 7B, meaning that the $m$ of this transition is large. However, in order to obtain stronger fluorescence and CD spectra, an intense $\mu$ is also desirable. Accordingly, planar molecules do not generally satisfy these two requirements. Compounds $\mathbf{H}_{\mathbf{2}}-\mathbf{2 5}$ and $\mathbf{Z n - 2 5}$ are helical molecules due to steric interaction of the pyridine moiety, so that they may satisfy these requirements after resolution of the enantiomers. Their precursor $\mathbf{2 4}$ was first prepared by reacting 2,6-diaminopyridine and substituent-free isoindolinediimine $\mathbf{f}$ at a ratio of $1: 2$, which was then reacted with two equivalents of 2-aminopyridine, to afford $\mathbf{H}_{2}-\mathbf{2 5}$. Resolution of $\mathbf{H}_{2}-\mathbf{2 5}$ into its enantiomers was unsuccessful, but after insertion of a $\mathrm{Zn}$ ion, $\mathbf{Z n - 2 5}$ was resolved into its $P$ - and $M$ enantiomers at $0^{\circ} \mathrm{C}$, due to relatively high solubility in a range of solvents. However, at room temperature, the enantiomers were racemized immediately due to a low energy barrier for racemization.

Figure 10 shows the X-ray structure of one enantiomer of each of $\mathbf{H}_{2}-\mathbf{2 5}$ and $\mathbf{Z n - 2 5}$, which have helical geometry due to 

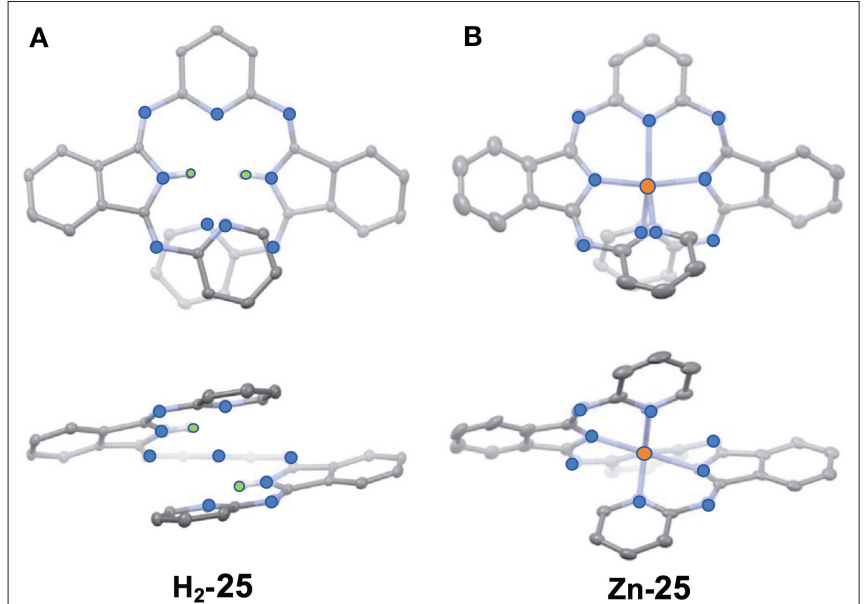

FIGURE 10 | X-ray structures of $\mathbf{H}_{\mathbf{2}} \mathbf{- 2 5}$ (A) and $\mathbf{Z n - 2 5}$ (B). The thermal ellipsoids are scaled to the $50 \%$ probability level. Hydrogen atoms except for $\mathrm{NH}$ hydrogens in $\mathbf{H}_{\mathbf{2}} \mathbf{- 2 5}$ are omitted for clarity. One of the two enantiomers is shown. Blue-, orange, and green circles indicate nitrogen, zinc, and hydrogen, respectively. Adapted from Tanaka et al. (2020).

steric repulsion between the pyridine moieties. All five nitrogen atoms in the pyridine and isoindoline moieties coordinate to the $\mathrm{Zn}$ (II) ion so that the central part is in a distorted trigonal bipyramidal geometry.

Figure 11A shows the absorption spectra of $\mathbf{H}_{2}-\mathbf{2 5}$ and $\mathbf{Z n -}$ 25. $\mathbf{H}_{2}-25$ exhibited a shoulder absorption at 380-500 $\mathrm{nm}$, and a similar weak band appeared for Zn-25 in 420-540 nm which could be assigned to a $\left(\mathrm{S}_{0}-\mathrm{S}_{1}\right) \pi-\pi^{*}$ transition (Muranaka et al., 2014). The molar extinction coefficient of $\mathbf{H}_{\mathbf{2}}-\mathbf{2 5}$ at $430 \mathrm{~nm}$ was ca. 3-4 times larger than that of conventional hemiporphyrazines, plausibly by ring-opening, suggesting that $\mu$ became larger. The calculated absorption spectra also support the observed spectra to a fair extent, and the oscillator strengths for the $\mathrm{S}_{0}-\mathrm{S}_{1}$ transition of $\mathbf{H}_{\mathbf{2}}-\mathbf{2 5}$ and $\mathbf{Z n - 2 5}$ were 0.16 and 0.11 , respectively, in comparison with 0.00 for hemiporphyrazine. As shown in Figure 11B, resolved enantiomers of Zn-25 exhibited $\mathrm{CD}$ and CPL envelopes of mirror symmetry in connection to the intensity $=0$ line. The glum value of $\mathbf{Z n - 2 5}$ at $535 \mathrm{~nm}$ was estimated by calculation to be $\pm 2.1 \times 10^{-2}$, representing one of the largest values among to date reported small helical molecules (Sanchez-Carnerero et al., 2015). The value of absorbance dissymmetry factor, $\mathrm{g}_{\mathrm{abs}}= \pm 2.6 \times 10^{-2}$, obtained experimentally from CD spectra at $520 \mathrm{~nm}$, was very close to the glum value in CPL spectra, suggesting that structural change was small upon excitation.

In order to elucidate the origin of the CPL properties, they performed $\mathrm{MO}$ analysis for the optimized $S_{1}$ state geometry of Zn-25 and hemiporphyrazine zinc complex as a reference. The properties of the associated HOMOs and LUMOs, such as coefficient values and nodal patterns and numbers, were retained even after structural modification to the helical geometry, and the estimated values of transition magnetic dipole moment $(m)$ for the $\mathrm{S}_{0}-\mathrm{S}_{1}$ transition of $(P)-\mathbf{Z n}-\mathbf{2 5}$ was $3.64 \mathrm{au}$, which was close to that of zinc hemiporphyrazine (4.35 au). The large glum value for $\mathbf{Z n - 2 5}$ was, therefore, taken to be related to the peculiar molecular orbital feature of the ringopened hemiporphyrazines.

A rigid CPL-active ring-unclosed hemiporphyrazine (H2-25') and its zinc complex (Zn-25') (Figure 6) were also synthesized by using 2-aminopyridine accompanying a chiral structure. As seen

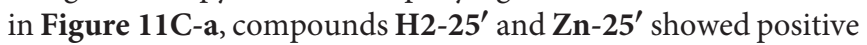
CPL spectra at ambient temperature without chiral HPLC separation $\left(\mathbf{H} 2-\mathbf{2 5}^{\prime}\right.$ : glum $=+6.5 \times 10^{-3}$ at $587 \mathrm{~nm}$ in toluene; Zn-25': glum $=+1.0 \times 10^{-2}$ at $573 \mathrm{~nm}$ in $\left.\mathrm{CHCl}_{3}\right)$, indicating that the ring-unclosed hemiporphyrazines with the right-handed $(P)$ helical structure were successfully obtained in a diastereoselective manner by covalently linking the chiral subgroup to the skeleton. The chiral recognition ability of $(R)$ - and $(S)-\mathbf{Z n - 2 5}$ was then examined by means of CPL spectroscopy since they racemized rapidly at ambient temperature. Here, when $(R)$ - or $(S)$ cyclohexylamine was added to a $\mathrm{CH}_{2} \mathrm{Cl}_{2}$ solution of $\mathbf{Z n - 2 5}$, a minus or plus CPL signal with a glum value of $\pm 1.3 \times 10^{-3}$ at $541 \mathrm{~nm}$ was recorded (Figure 11C-b), depending on the chirality of amine. Afterall, this phenomenon could be rationalized by means of the induction of helical chirality via ligation of the chiral amine to the central zinc ion. Thus, since the helical structure of $\mathbf{Z n - 2 5}$ is flexible, it can be utilized as a dynamic chiral recognition/sensing tool.

\section{CONCLUSIONS AND OUTLOOK}

Optically-active Pcs and their congeners are expected to be the subject of ongoing reports. As seen in this review, those containing chiral binaphthyls may become an important topic in future publications, for several conceivable reasons: easy and high-yield preparation of precursors from commercially available compounds, i. e. $\mathbf{a}$ and $\mathbf{b}$ in Figure 1; no racemization of $\mathbf{a}$ and $\mathbf{b}$ during macrocyclic formation reaction; and anticipated strong $\mathrm{CD}$ and ICD intensity and relatively easy theoretical analysis of the spectroscopic properties of the resultant compounds. In particular, since enantiopure $(R, R)$ - and $(S, S)-2,2^{\prime}$-dihydroxybinaphthyl are commercially available, researchers will continue to use these precursors often. Since the synthesis and CD properties of normal compounds are no longer uniquely interesting, because two enantiomers always afford $\mathrm{CD}$ of mirror image with respect to the $[\theta]=0$ line, it is important to produce compounds which have spectroscopically intriguing properties, and to analyze the data theoretically if needed with the help of quantum chemical calculations. In most papers including chiral binaphthyl units published over the past decade, however, no analysis of CD spectra has been given, unfortunately.

The studies of Pc derivatives substituted by long alkyl chains have mostly been related to liquid crystals. Interestingly, it was found and established by Ohta et al. that some of the achiral dyads based on $\mathrm{Pc}$ and fullerene $\left(\mathrm{Pc}_{\mathrm{C}} \mathrm{C}_{60}\right)$ show a unique helical structure in the liquid crystalline phases (= mesophases) (Tauchi 

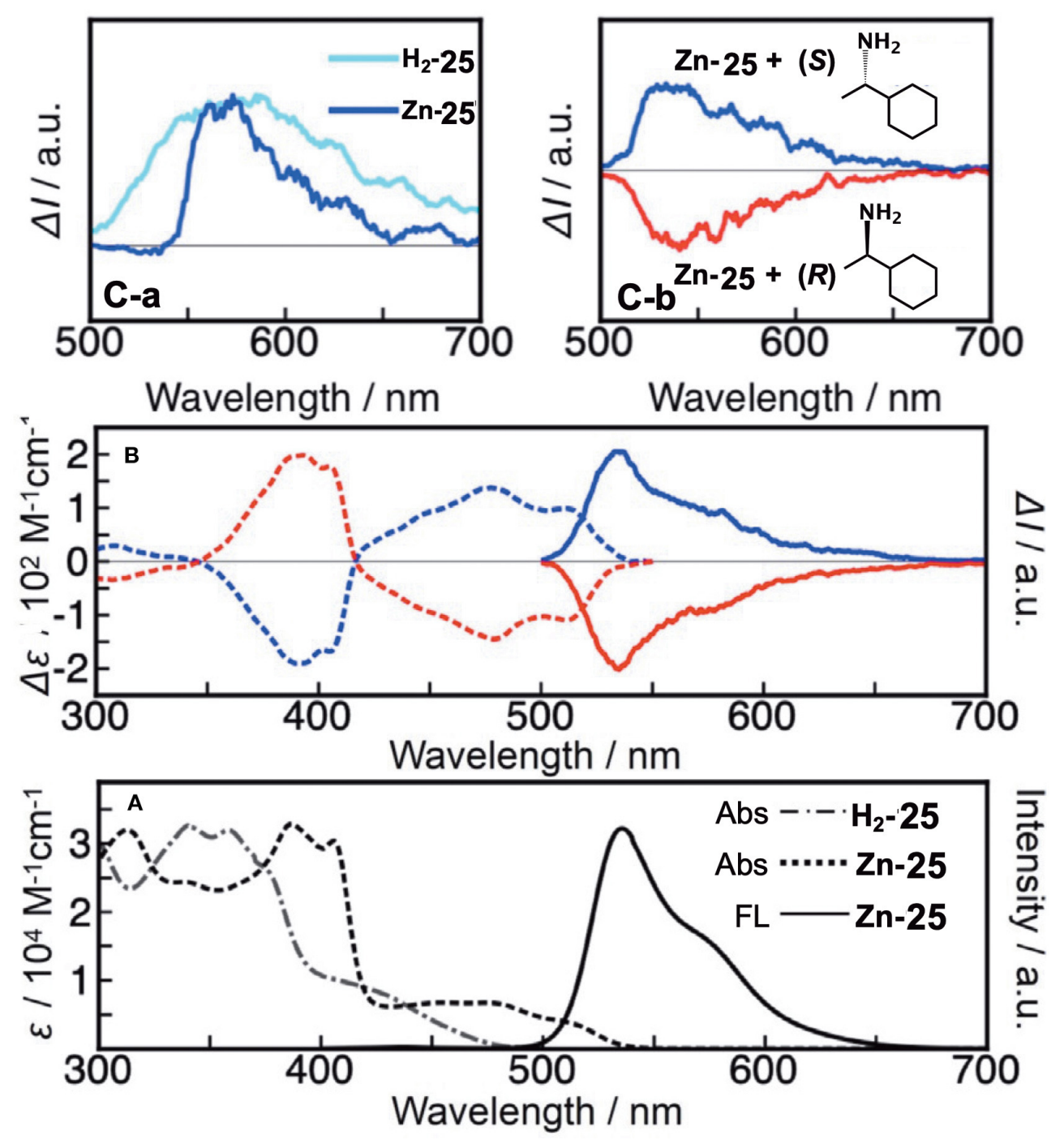

FIGURE 11 | (A) Electronic absorption and fluorescence spectra of $\mathbf{H}_{\mathbf{2}} \mathbf{- 2 5}$ and $\mathbf{Z n - 2 5}$ in $\mathrm{CH}_{2} \mathrm{Cl}_{2}$ at ambient temperature. (B) CD and CPL signals of $\mathbf{Z n - 2 5}$ in $n$-hexane/THF/diethylamine $=80: 20: 0.1$ ( $/$ / / v) (first fraction, blue line; second fraction, red line). According to the TDDFT calculations, the first and second fractions were respectively assigned as right-handed $(P)$ - and left-handed $(M)-\mathbf{Z n - 2 5}$. (C-a) CPL signals of ring-unclosed hemiporphyrazines bearing chiral units $\left(\mathbf{H}_{\mathbf{2}} \mathbf{- 2} \mathbf{2 5}^{\prime}\right.$ in toluene and $\mathbf{Z n - 2 5}$ in $\mathbf{C H C l}_{3}$ ) at ambient temperature. (C-b) CPL signals of $\mathbf{Z n - 2 5}$ in the presence of $(S)$ - or $(R)$-1-cyclohexylethylamine.

et al., 2010). However, a problem is that some researchers did not have enough expertise on the mesophase structural analysis. For example, a paper from a high-level university reported that other $\mathrm{Pc}_{-} \mathrm{C}_{60}$ based-dyads exhibit the helicity, although their assigned mesophase cannot show theoretically a homeotropic alignment necessary for the establishment of the helicity (Hayashi et al., 2011, 2017). The authors assigned a faint shoulder in a diagram of temperature-variable X-ray diffraction measurements (XRD pattern) to the helicity, but the homeotropic alignment should not appear theoretically for their assigned mesophase. This assignment was later shown to be false in a detailed study using compounds having similar structures by a group of liquid crystal specialists (Ishikawa et al., 2018). Thus, researchers of liquid crystals are recommended to learn more about the analysis of mesophase data. In this respect, a nice textbook was published recently (Ohta, 2020).

In the work introduced here as Pc congeners, for example, Muranaka's 19-21 were interesting. Although the structures were similar, depending on the element included, the spectra changed between those of $4 n \pi$ and $(4 n+2) \pi$ systems, and in the case of the VO complex of $4 n \pi$ anti-19, the two enantiomers showed an intense $\mathrm{CD}$ in the region where rotation of charge is expected theoretically. This became possible since in $4 n \pi$ compounds, the HOMO-LUMO transition has essentially an intrashell nature 
(magnetic dipole allowed transition), and this kind of theme cannot be easily pursued without having some knowledge on spectroscopy. Rather than Pc itself, attractive compounds may be found more easily in Pc-related congeners, since structural modification possibilities are huge, and new ideas can come easily from researchers who always seek for fantastic azamacrocycles. In addition, the formation of some achiral dyad and triad systems that form helicity or chirality appears to be a challenging theme to be pursued going forward, in order to elucidate its driving force.

\section{REFERENCES}

Bacilla, A. C. C., Okada, Y., Yoshimoto, S., Islyaikin, M. K., Koifman, K. I., and Kobayashi, N. (2020). Triangular expanded hemiporphyrazines: electronic structures and nanoscale characterization of their adlayers on $\mathrm{Au}(111)$. Bull. Chem. Soc. Jpn. 93. doi: 10.1246/bcsj.20200188

Basova, T., Hassan, A., Durmus, M., Gurek, A. G., and Ahsen, V. (2016). Liquid crystalline metal phthalocyanines: structural organization on the substrate surface. Coord. Chem. Rev, 310, 131-153. doi: 10.1016/j.ccr.2015.11.005

Claessens, C. G., Gonzales-Rodriguez, D., Rodriguez-Morgade, M. S., Medina, A., and Torres, T. (2014). Subphthalocyanines, subporphyrazines, and subporphyrins: singular nonplanar aromatic systems. Chem. Rev. 114, 2192-2277. doi: $10.1021 / \mathrm{cr} 400088 \mathrm{w}$

Claessens, C. G., Gonzales-Rodriguez, D., and Torres, T. (2002). Subphthalocyanines: singular nonplanar aromatic compoundssynthesis, reactivity, and physical properties. Chem. Rev. 102, 835-854. doi: $10.1021 / \mathrm{cr} 0101454$

Filatov, M. S., Trukhina, O. N., Rodriguez-Morgade, M. S., Islyaikin, M. K., Koifman, O. I., and Torres, T. (2014). Synthesis and spectroscopic properties of chiral bornane[2,3-b]pyrazino-fused [30]trithiadodecaazahexaphyrins. J. Porphyrins Phthalocyanines 18, 1014-1020. doi: 10.1142/1088424614500771

Fleischhauer, J., Höweler, U., and Michl, J. (2000). MCD of nonaromatic cyclic $\pi$-electron systems. 3 . The perimeter model for low-symmetry "unaromatic" and "ambiaromatic" molecules derived from $4 \mathrm{~N}$-electron [n] annulenes. J. Phys. Chem. A. 104, 7762-7775. doi: 10.1021/jp000116h

Fleischhauer, J., Höweler, U., Spanget-Larsen, J., Raabe, G., and Michl, J. (2004). MCD of nonaromatic cyclic $\pi$-electron systems. 5 . Biphenylene and its aza analogues. J. Phys. Chem. A. 108, 3225-3234. doi: 10.1021/jp037806g

Fleischhauer, U., Raabe, G., Klingensmitj, K. A., Höweler, U., Chattrjee, R. K., Hafner, K., et al. (2005). MCD of nonaromatic cyclic $\pi$-electron systems. Part 6: pentalenes and heptalenes. Int. J. Quantum Chem. 102, 925-939. doi: 10.1002/qua.20453

Fukuda, T., and Kobayashi, N. (2010). "Electronic absorption spectraphthalocyanines," in Handbook of Porphyrin Science, Vol. 9, Chapter 42, eds K. M. Kadish, K. M. Smith, and R. Guilard (Singapore: World Scientific), 1-650.

Giménez-Agulló, N., Aragay, G., Galán-Mascarós, J. R., and Ballester, P. (2016). Study of the Coordination of Quinuclidine to a Chiral Zinc Phthalocyanine Dimer. J. Porphyrins Phthalocyanines 20, 1224-1232. doi: 10.1142/S1088424616500929

Gok, Y., Gok, H. Z., and Karayigit, I. U. (2018). Synthesis, characterization and aggregation properties of non-peripherally $(1 R, 2 R)-1,2-\mathrm{Di}$ (naphthalen1-yl)ethane-1,2-diol substituted optically active zinc phthalocyanine and its catalytic application in enantioselective ethylation of aldehydes. J. Orgmet. Chem. 873, 43-49. doi: 10.1016/j.jorganchem.2018.07.033

Hayashi, H., Nihashi, W., Ueyama, T., Matano, Y., Seki, S., Shimizu, Y., et al. (2011). Segregated donor-acceptor columns in liquid crystals that exhibit highly efficient ambipolar charge transport. J. Am. Chem. Soc. 133, 10736-10739. doi: 10.1021/ja203822q

Hayashi, H., Nihashi, W., Ueyama, T., Matano, Y., Seki, S., Shimizu, Y., et al. (2017). Correction to "segregated donor-acceptor columns in liquid crystals that exhibit highly efficient ambipolar charge transport". J. Am. Chem. Soc. 139, 13957-13957. doi: 10.1021/jacs.7b09424

Howeler, U., Downing, J. W., Fleischhauer, J., and Michl, J. (1998). MCD of non-aromatic cyclic $\pi$-electron systems. Part 1 . The perimeter model for

\section{AUTHOR CONTRIBUTIONS}

YO prepared the figures. TH collected the reference papers. NK wrote the text. All authors contributed to the article and approved the submitted version.

\section{FUNDING}

This work was supported in part by JSPS KAKENHI, grant number 18K05076.

antiaromatic $4 \mathrm{~N}$-electron [n]annulene biradicals. J. Chem. Soc. Perkin Trans. 2, 1101-1117. doi: 10.1039/A800088C

Ishikawa, K., Watarai, A., Yasugtake, M., and Ohta, K. (2018). Discotic liquid crystals of transition metal complexes 56: synthesis of mesogenic phthalocyanine-fullerene dyads and Influence of the substitution position of alkoxy chains and the kind of terminal groups on appearance of the helical supramolecular structure. J. Porphyrins Phthalocyanines 22, 693-715. doi: 10.1142/S108842461850092X

Kadish, K. M., Smith, K. M., and Guilard, R. (2000). The Porphyrin Handbook, Vol. 6, eds K. M. Kadish, K. M. Smith, and R. Guilard (New York, NY: Academic Press), 1-346.

Kadish, K. M., Smith, K. M., and Guilard, R. (2003a). The Porphyrin Handbook, Vol. 19, eds K. M. Kadish, K. M. Smith, and R. Guilard (New York, NY: Academic Press), 1-194.

Kadish, K. M., Smith, K. M., and Guilard, R. (2003b). The Porphyrin Handbook, Vol. 14, eds K. M. Kadish, K. M. Smith, and R. Guilard (New York, NY: Academic Press), 1-347.

Kitagawa, Y., Miyatake, T., and Ishii, K. (2012). Magneto-chiral dichroism of artificial light-harvesting antenna. Chem. Commun. 48, 5091-5093. doi: 10.1039/C2CC30996C

Kitagawa, Y., Segawa, H., and Ishii, K. (2011). Magneto-chiral dichroism of organic compounds. Angew. Chem. 123, 9299-9302. doi: 10.1002/ange.201101809

Kobayashi, N. (1998). Optically active 'adjacent' type non-centrosymmetrically substituted phthalocyanines. Chem. Commun. 1998, 487-488. doi: 10.1039/A708343B

Kobayashi, N. (2001). Optically active phthalocyanines. Coord. Chem. Rev. 221/222, 99-123. doi: 10.1016/S0010-8545(01)00 323-X

Kobayashi, N. (2002). "Synthesis and spectroscopic properties of phthalocyanine analogues," in Handbook of Porphyrins and Related Macrocycles, Vol. 15, Chapter 100, eds K. M. Kadish, K. M. Smith, and R. Guilard (New York, NY: Academic Press), 161-262.

Kobayashi, N. (2010). "Optically active porphyrin systems analyzed by circular dichroism," in Handbook of Porphyrin Science, Vol. 7, Chapter 33, eds K. M. Kadish, K. M. Smith, and R. Guilard (Singapore: World Scientific), 147-245.

Kobayashi, N. (2012). "Synthesis and characterization of chiral phthalocyanines," in Handbook of Porphyrin Science, Vol. 23, Chapter 110, eds K. M. Kadish, K. M. Smith, and R. Guilard (Singapore: World Scientific), 373-440.

Kobayashi, N., Higashi, R., Titeca, B. C., Lamote, F., and Ceulemans, A. (1999a). Substituent induced circular dichroism in phthalocyanines. J. Am. Chem. Soc. 121, 12018-12028. doi: 10.1021/ja992556w

Kobayashi, N., Ishizaki, T., Ishii, K., and Konami, H. (1999b). Synthesis, spectroscopy, and molecular orbital calculations of subazaporphyrins, subphthalocyanines, subnaphthalocyanines, and compounds derived therefrom by ring expansion. J. Am. Chem. Soc. 121, 9096-9110. doi: 10.1021/ja983325c

Kobayashi, N., and Konami, H. (1996). "Electronic spectra and molecular orbitals of phthalocyanines," in Phthalocyanines-Properties and Applications, Vol. IV, Chapter 6, eds C. C. Leznoff and A. B. P. Lever (New York, NY; Weinheim; Cambridge: VCH), 343-404.

Kobayashi, N., Kondo, R., Nakajima, S., and Osa, T. (1990). New route to unsymmetrical phthalocyanine analogues by the use of structurally distorted subphthalocyanines. J. Am. Chem. Soc. 112, 9640-9641. doi: $10.1021 /$ ja00182a034 
Kobayashi, N., Muranaka, A., and Mack, J. (2012). Circular Dichroism and Magnetic Circular Dichroism Spectroscopy for Organic Chemists. London: Royal Society of Chemistry.

Kobayashi, N., Narita, F., Ishii, K., and Muranaka, A. (2009). Optically active oxo(phthalocyaninato)vanadium(IV) with geometric asymmetry: synthesis and correlation between the circular dichroism sign and conformation. Chem. Eur. J. 15, 10173-10181. doi: 10.1002/chem.200901306

Kobayashi, N., and Nevin, W. A. (1998). Optically active tetrapyrazinoporphyrazines and their circular dichroism in monomeric and dimeric forms. Chem. Lett. 1998, 851-852. doi: 10.1246/cl.1998.851

Lin, S., Ji, L., Jing, L., Lu, J., Wang, H., Sun, S., et al. (2015). Helical self-assembly and nonlinear optical properties of two optically active phthalocyanine derivatives with the same chiral substituents on the a or b position. Inorg. Chim. Acta 434, 24-30. doi: 10.1016/j.ica.2015.05.006

Lu, H., and Kobayashi, N. (2016). Optically active porphyrin and phthalocyanine systems. Chem. Rev. 116, 6184-6261. doi: 10.1021/acs.chemrev.5b00588

Lu, J., Deng, Y., Zhang, X., Kobayashi, N., and Jiang, J. (2011). Optically Active Mixed (Phthalocyaninato)(Porphyrinato) Rare Earth Triple-Decker Complexes. Synthesis, Spectroscopy, and Effective Chiral Information Transfer, Inorg. Chem., 50, 2562-2567. doi: 10.1021/ic102393c

Lunkley, J. L., Shirotani, D., Yamanari, K., Kaizaki, S., and Muller, G. (2008). Extraordinary circularly polarized luminescence activity exhibited by cesium tetrakis(3-heptafluoro-butylryl-(+)-camphorato) Eu(III) complexes in $\mathrm{EtOH}$ and $\mathrm{CHCl}_{3}$ solutions. J. Am. Chem. Soc. 130, 13814-13815. doi: $10.1021 / \mathrm{ja} 805681 \mathrm{w}$

Michl, J. (1978a). Magnetic circular dichroism of cyclic p-electron systems. 1. Algebraic solution of the perimeter model for the A and B terms of highsymmetry systems with a $(4 \mathrm{~N}+2)$ p-electron [n] annulene perimeter. J. Am. Chem. Soc. 100, 6801-6811. doi: 10.1021/ja00490a001

Michl, J. (1978b). Magnetic circular dichroism of cyclic $\pi$-electron systems. 3. Classification of cyclic $\pi$ chromophores with a $(4 \mathrm{~N}+2) \pi$-electron [n]annulene perimeter and general rules for substituent effects on the MCD spectra of soft chromophores. J. Am. Chem. Soc. 100, 6819-6824. doi: $10.1021 /$ ja00490a003

Michl, J. (1978c). Magnetic circular dichroism of cyclic $\pi$-electron systems. 2. Algebraic solution of the perimeter model for the B terms of systems with a $(4 \mathrm{~N}+2) \pi$-electron [n] annulene perimeter. J. Am. Chem. Soc. 100, 6812-6818. doi: $10.1021 / \mathrm{ja} 00490 \mathrm{a} 002$

Michl, J. (1980). Electronic structure of aromatic $\pi$-electron systems as reflected in their MCD spectra. Pure Appl. Chem. 52, 1549-1563. doi: 10.1351/pac198052061549

Muranaka, A., Matsumoto, Y., Uchiyama, M., Jiang, J., Bian, Y., Ceulemans, A., et al. (2005). Definitive assignments of the visible-near-IR bands of porphyrinnaphthalocyanine rare-earth sandwich double- and triple-decker compounds by magnetic circular dichroism spectroscopy. Inorg. Chem. 44, 3818-3826. doi: $10.1021 /$ ic 0502325

Muranaka, A., Matsushita, O., Yoshida, K., Mori, S., Suzuki, M., Furuyama, T., et al. (2009). Application of the perimeter model to the assignment of the electronic absorption spectra of gold(III) hexaphyrins with [4n +2$]$ and [4n] $\pi$-electron systems. Chem. Eur. J. 15, 3744-3751. doi: 10.1002/chem.200801742

Muranaka, A., Ohira, S., Toriumi, N., Hirayama, M., Kyoutani, F., Mori, Y., et al. (2014). Unraveling the electronic structure of azolehemiporphyrazines: direct spectroscopic observation of magnetic dipole allowed nature of the lowest $\pi$ $\pi^{*}$ transition of $20 \pi$-electron porphyrinoids. J. Phys. Chem. A 118, 4415-4424. doi: $10.1021 /$ jp5001557

Ohta, K. (2020). Physics and Chemistry of Molecular Assemblies. Singapore: World Scientific.

Ohta, K., Nguyen-Tran, H. -D., Tauchi, L., Kanai, Y., Megumi T, and Takagi, Y. (2011). "Liquid crystals of phthalocyanines, porphyrins and related compounds," in Handbook of Porphyrin Science With Applications to Chemistry, Physics, Materials Science, Engineering, Biology and Medicine, Volume 12: Applications, Chapter 53, eds K. M. Kadish, K. M. Smith, and R. Guilard (Singapore: World Scientific), 1-120. doi: 10.1142/9789814322386_0005

Revuelta-Maza, M. A., Torres, T., and Torre, G. (2019). Synthesis and aggregation studies of functional binaphthyl-bridged chiral phthalocyanines. Org. Lett. 21, 8183-8186. doi: 10.1021/acs.orglett.9b02718

Riehl, J. P., and Richardson, F. S. (1986). Circularly polarized luminescence spectroscopy. Chem. Rev. 86, 1-16. doi: 10.1021/cr00071a001
Sanchez-Carnerero, E. M., Agarrabeitia, A. R., Moreno, F., Maroto, B. L., Muller, G., Ortiz, M. J., et al. (2015). Circularly polarized luminescence from simple organic molecules. Chem. Eur. J. 21, 13488-13500. doi: $10.1002 /$ chem. 201501178

Shimizu, S., Miura, A., Khene, S., Nyokong, T., and Kobayashi, N. (2011). Chiral 1,2-subnaphthalocyanines. J. Am. Chem. Soc. 133, 17322-17328. doi: $10.1021 / \mathrm{ja} 2052667$

Shimizu, S., Otaki, T., Yamazaki, Y., and Kobayashi, N. (2012). Synthesis and properties of $\beta, \beta-s p^{3}$-hybridized subphthalocyanine analogues. Chem. Commun. 48, 34100-34002. doi: 10.1039/c2cc30511a

Tanaka, Y., Maruyama, T., Mureanaka, A., Imai, E., and Uchiyama, M. (2020). Ring-opened hemiporphyrazines: helical molecules exhibiting circularly polarized luminescence. Chem. Eur. J. 26, 1768-1771. doi: $10.1002 /$ chem. 201905246

Tauchi, L., Shimizu, M., Fujii, T., Nguyen-Tran, H. -D., Kamei, T., and Ohta, $\mathrm{T}$ (2010). "Mesogenic phthalocyanineffullerene dyad showing homeotropic alignment and helical structure," in 23rd International Liquid Crystal Conference (Krakow), P1.106.

Tian, J., Jing, L., Zhang, C., Ji, L., Zhu, P., and Zhang, X. (2013a). Helical selfassembly of optically active phthalocyanine derivatives bearing four optically active (S)-2-methylbutoxy moieties at the $\alpha$ position of the phthalocyanine ring. Eur. J. Inorg. Chem. 2013, 5281-5287. doi: 10.1002/ejic.201300564

Tian,. J., Jing, L., Ji, L., Zhang, C., Liu, Q., and Zhang, X. (2013b). Helical selfassembly and nonlinear optical properties of optically active phthalocyanine derivatives bearing eight optically active diethyleneglycol mono-(S)-2methylbutyl ether moieties on the $\beta$-position of the phthalocyanine ring. RSC Adv. 3, 22461-22468. doi: 10.1039/c3ra44164d

Wang, K., Wang, H., Li, W., Kobayashi, N., and Jiang, J. (2012). Chiral phthalocyanine with unambiguous absolute molecular structures for both enantiomers. Acta Chim. Sin. 70, 1791-1797. doi: 10.6023/A12050262

Wang, K., Zeng, S., Wang, H., Dou, J., and Jiang, J. (2014). Magneto-chiral dichroism in chiral mixed (phthalocyaninato)(porphyrinato) rare earth tripledecker SMMs. Inorg. Chem. Front. 1, 167-171. doi: 10.1039/c3qi00097d

Wu, Y., Gai, L., Xiao, X., Lu, H., Li, Z., Mack, J., et al. (2016). A chiral hemiporphyrazine derivative: synthesis and chiroptical properties. Chem. Asian. J. 11, 2113-2116. doi: 10.1002/asia.201600754

Zhang, C., Jing, L., Lin, S., Hao, Z., Tian, J., Zhang, X., et al. (2013). Helical self-assembly of optically active phthalocyanine derivatives: effect of $\mathrm{Zn}$ $\mathrm{O}$ coordination bond on morphology and handedness of nanostructures. ChemPhysChem 14, 3827-3833. doi: 10.1002/cphc.201300604

Zhang, W., Fujiki, M., and Zhu, X. (2011). Chiroptical nanofibers generated from achiral metallophthalocyanines induced by diamine homochirality. Chem. Eur. J. 17, 10628-10635. doi: 10.1002/chem.201100208

Zhang, Y., Zhao, L., Wang, K., and Jiang, J. (2017). Unprecedented phthalocyanine-porphyrin-fused oligomers with induced chirality nature. Inorg. Chem. Front. 4, 104-109. doi: 10.1039/c6qi00496b

Zhao, L., Wang, K., Furuyama, T., Jiang, J., and Kobayashi, N. (2014). Synthesis and spectroscopic properties of chiral binaphthyl-linked subphthalocyanines. Chem. Commun. 50, 7663-7665. doi: 10.1039/c4cc03426k

Zhao, L., Wang, K., Shang, H., and Jiang, J. (2015). Novel chiral ABBB-type unsymmetrical phthalocyanine. Ring-expansion synthesis, spectroscopic, and electrochemical properties. Dyes Pigments 120, 52-56. doi: 10.1016/j.dyepig.2015.04.009

Zhou, H., Wang, K., Qi, D., and Jiang, J. (2014). Chiral bis(phthalocyaninato) yttrium double- decker complexes. Synthesis, structure, spectroscopy, and electrochemistry. Dalton Trans. 43, 1699-1705. doi: 10.1039/c3dt52611a

Conflict of Interest: The authors declare that the research was conducted in the absence of any commercial or financial relationships that could be construed as a potential conflict of interest.

Copyright $\odot 2020$ Okada, Hoshi and Kobayashi. This is an open-access article distributed under the terms of the Creative Commons Attribution License (CC BY). The use, distribution or reproduction in other forums is permitted, provided the original author(s) and the copyright owner(s) are credited and that the original publication in this journal is cited, in accordance with accepted academic practice. No use, distribution or reproduction is permitted which does not comply with these terms. 